فاعلية برناهج تدريبي لتنـية ههارات التطريز الآلي لتأهيل الخريجات

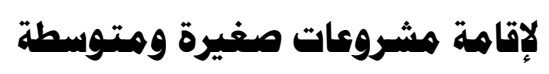

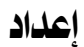 \\ د/ نجلاء محمد أحمد ماضحس. \\ أستاذ الملابس والنسيج المساعد - قسم الاقتصاد المنزلي \\ كلية التربية النوعية- جامعة المنصورة
}

مجلة بجوث التربية النوعية ـ جامعة المنصورة

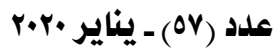


يهدف البحث الي اعداد برنامـج تدريبي لتنمية مهارات التطريز الالي للخريجات لتأهيلهم التهات

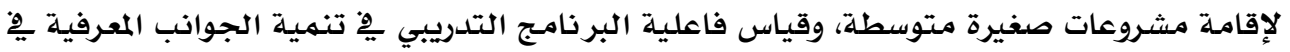

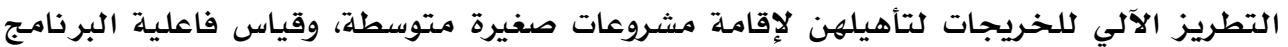

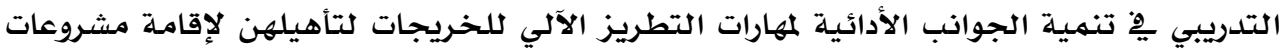

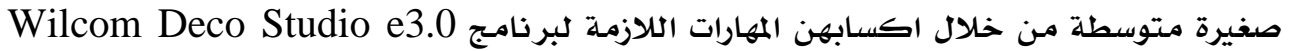
وتشغيل ماكينة التطريز (TWJIMA C1501) وقد واتبع البحث المنهج التطبيقي وكانت العينة قصديه وعددهم (ro) من خريجات

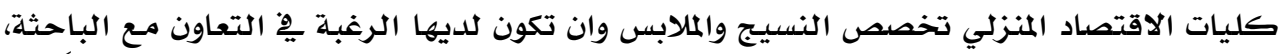

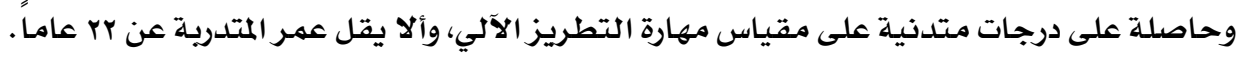

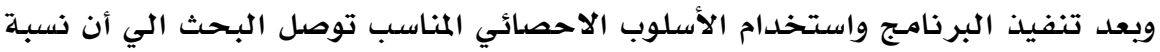

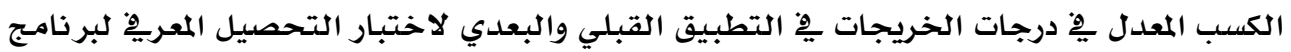
(TAJIMA TWMX C1501. وماكينة التطريز (1.68) Wilcom DecoStudio e3.0

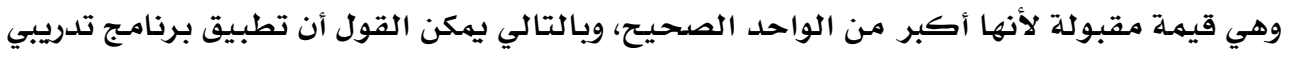

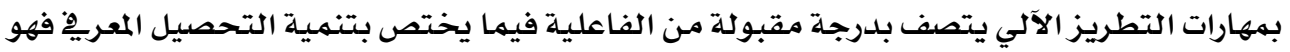

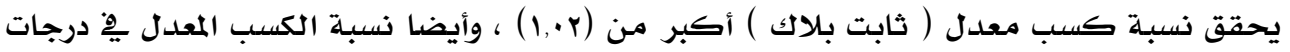

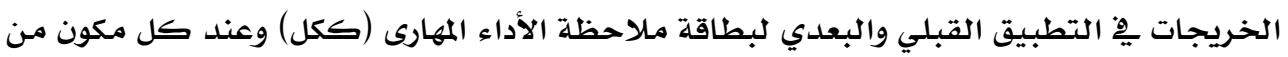

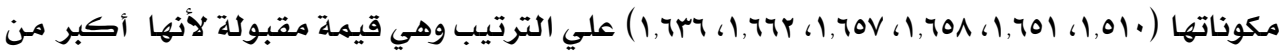

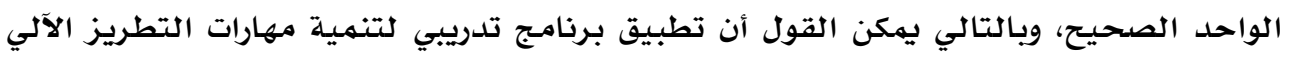

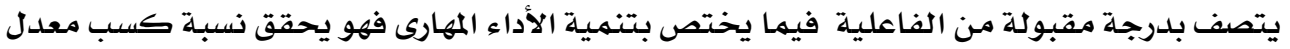

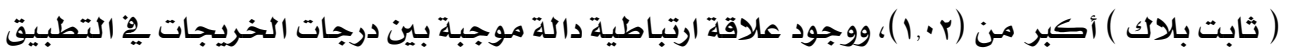

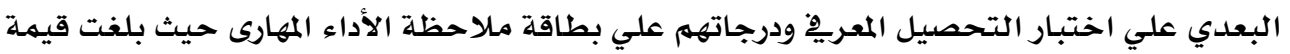

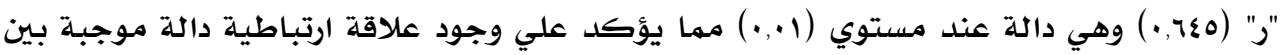

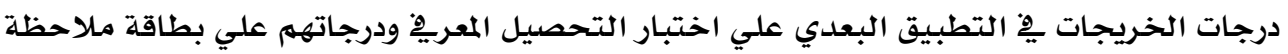


الأداء المهارى وبالتالي يهكن القول أن تطبيق برنامج تدريبي بههارات التطريز الآلي يتصف بـرجة مقبولة من الفاعلية

همبدة

تواجه مصر حاليا كسائر الدول النامية تحديات كبري علمية وتقنيه واقتصادية

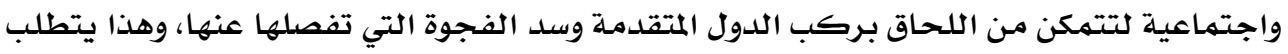

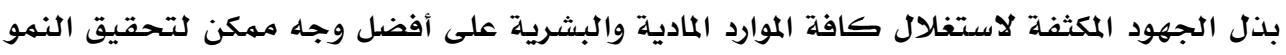

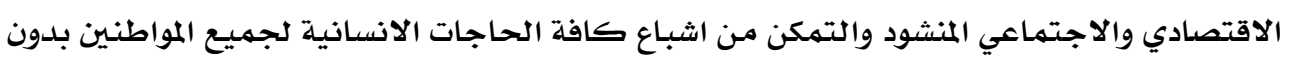
تمييز.

وتعد الصناعات الصغيرة ذات أهمية كبيري يِّ جميع دول العالم وخاصدة الدول النامية ،

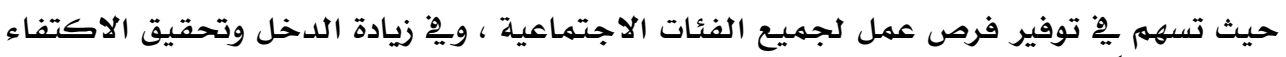

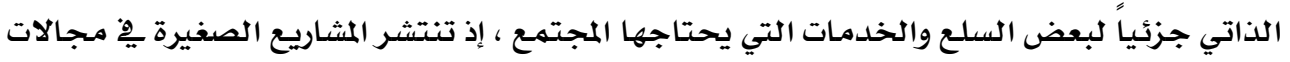

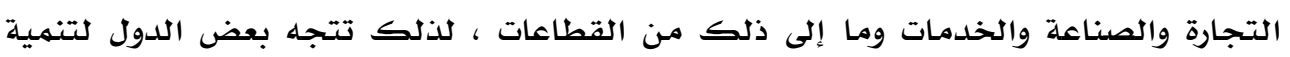

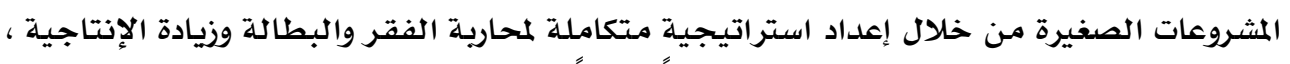

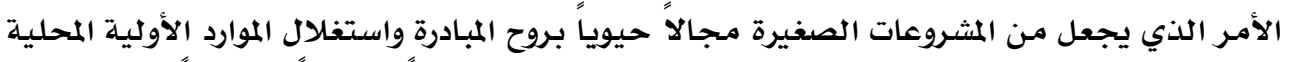

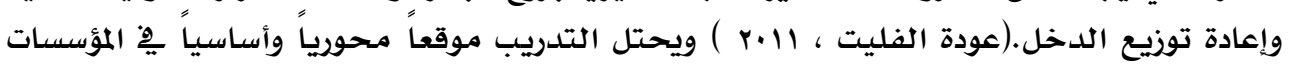

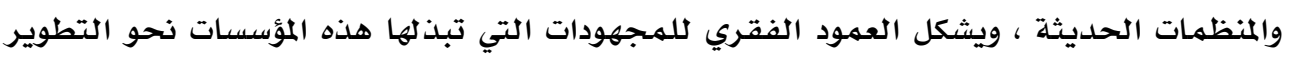

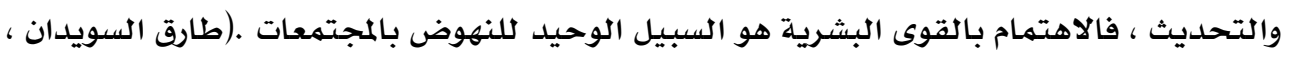

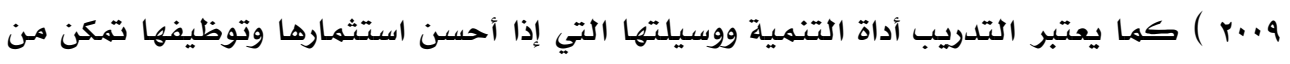

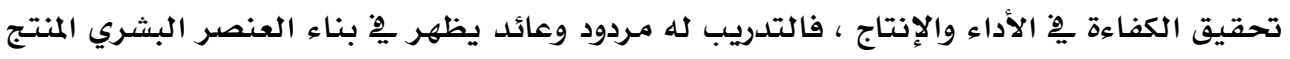

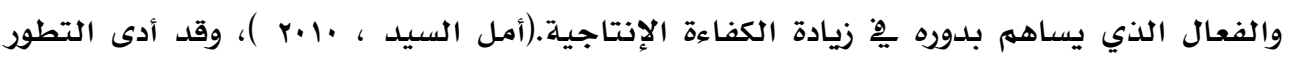

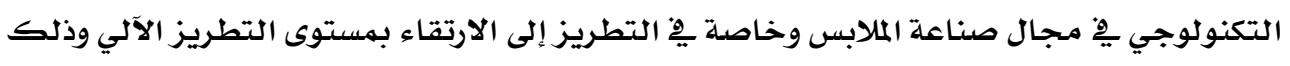

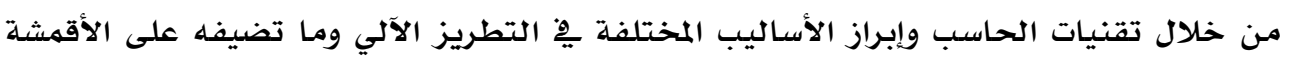

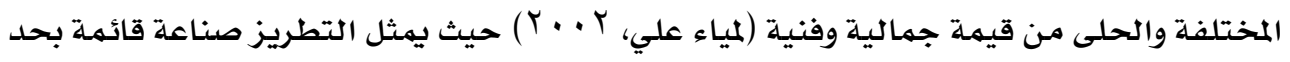

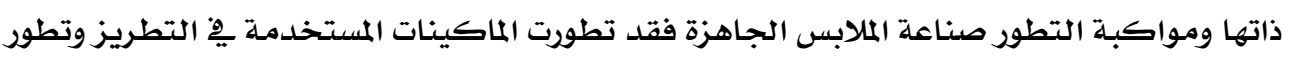

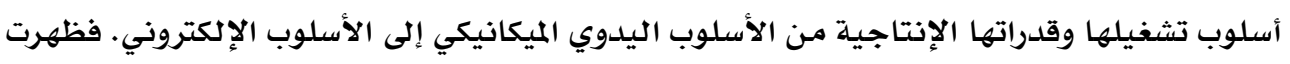

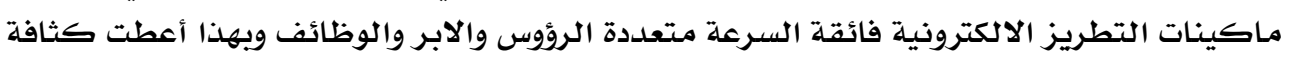

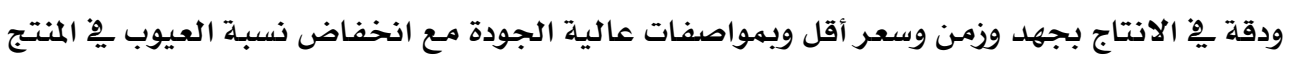

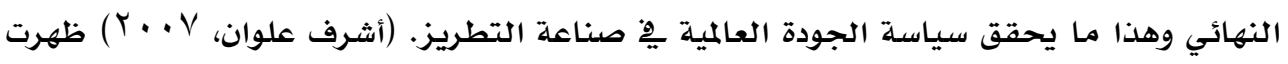

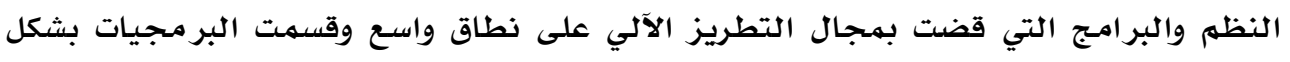

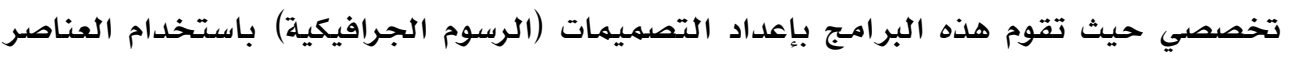

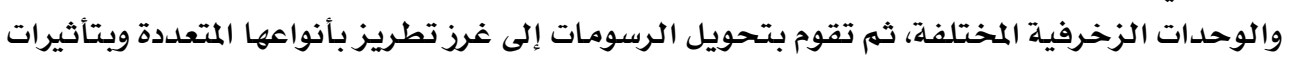

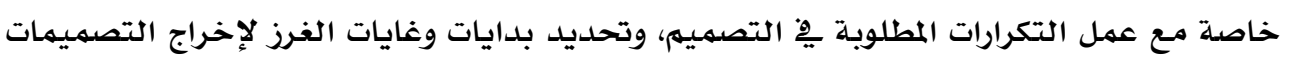




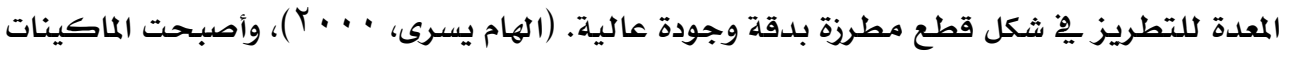

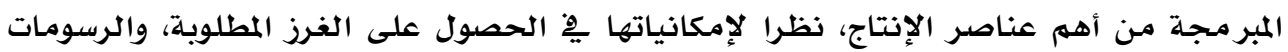

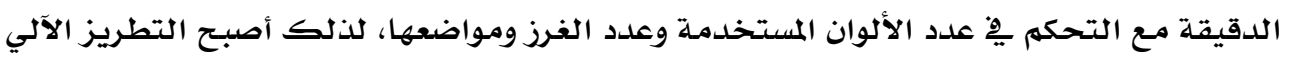

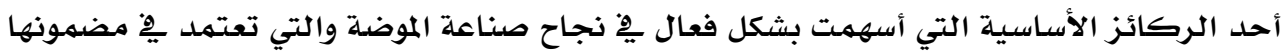

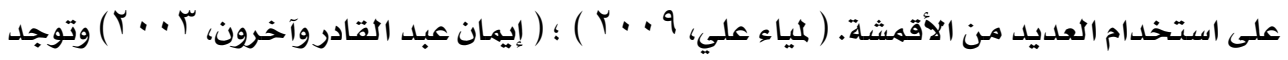

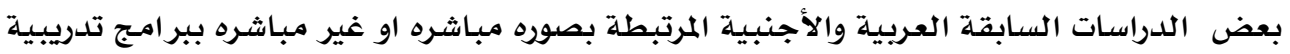

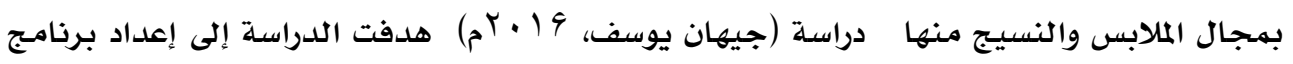

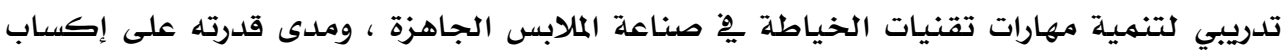

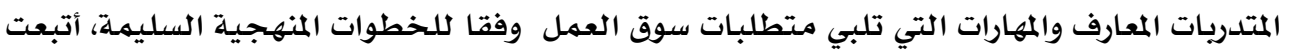

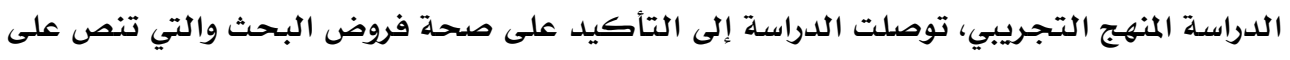

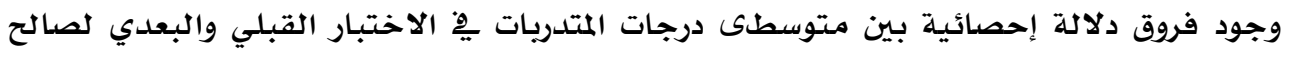

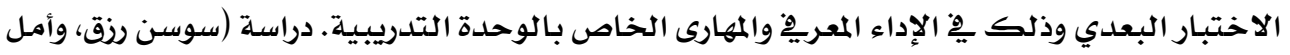

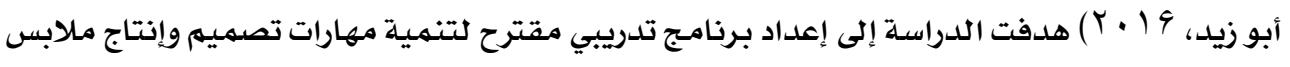

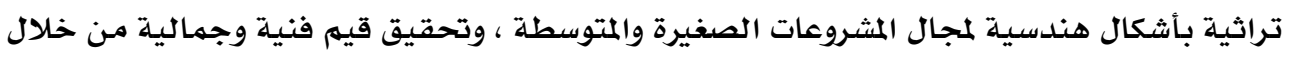

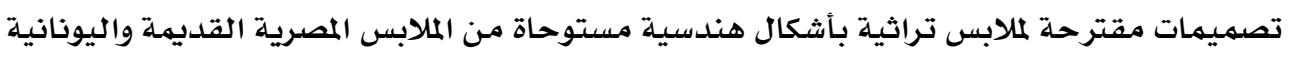

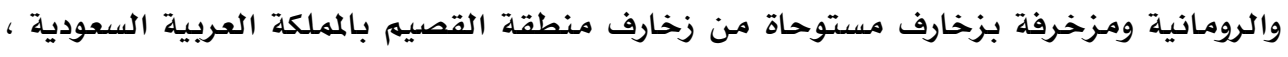

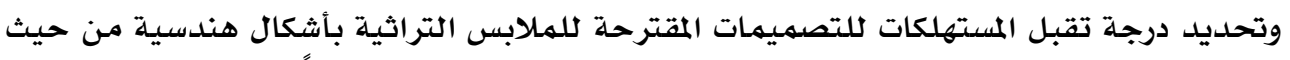

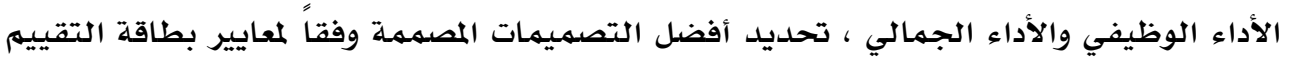

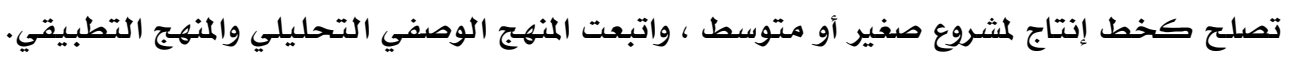

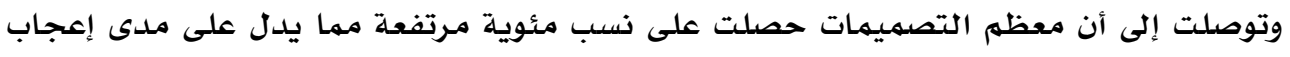

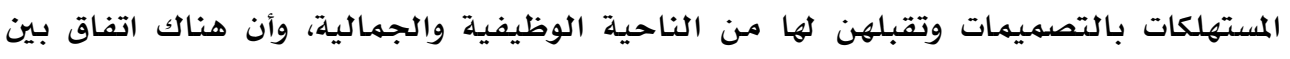

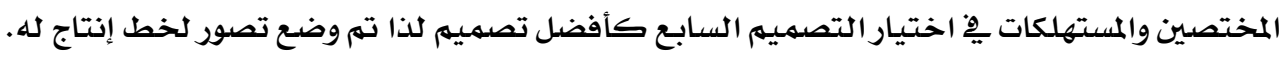

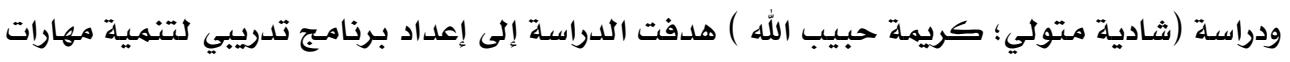

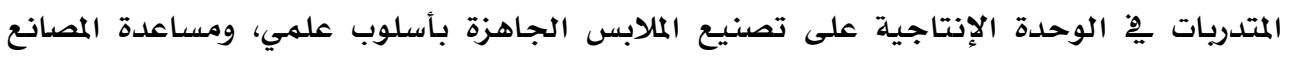

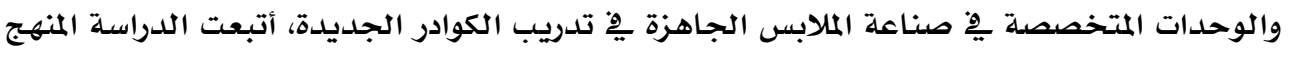

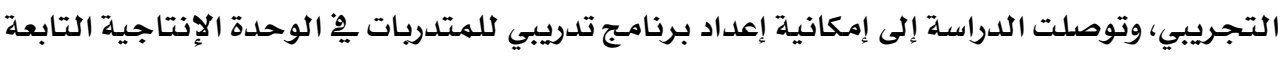

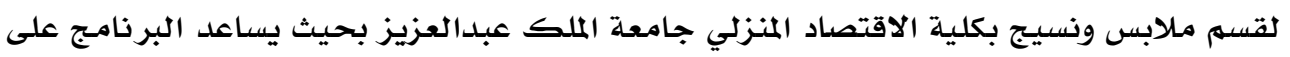

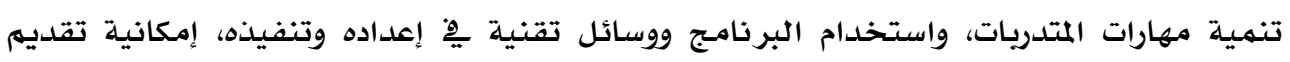

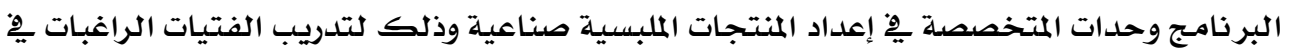

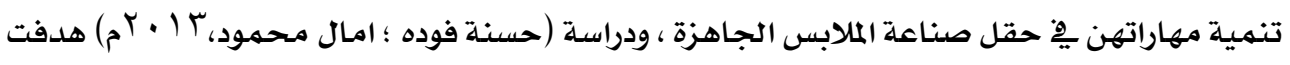

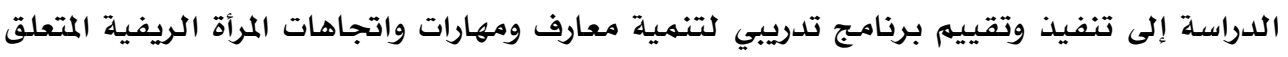

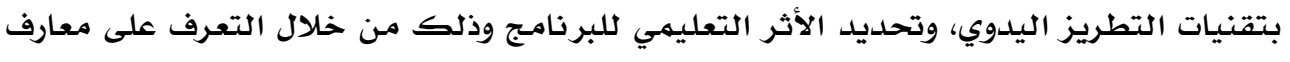

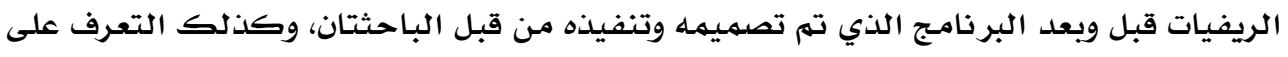


مهارات واتجاهات الريفيات نحو إقامـة مشروعات صغيرة تعتمد على التطريز اليدوي قبل وبعد

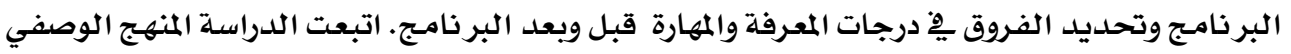

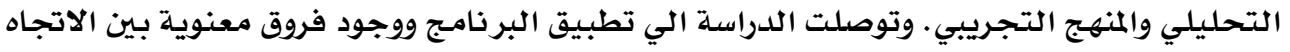

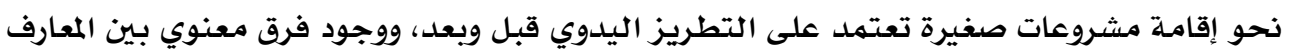

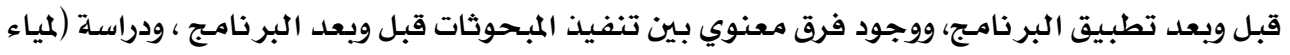

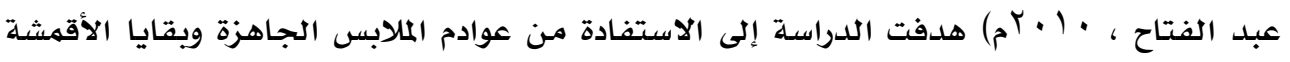

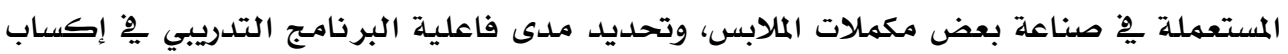

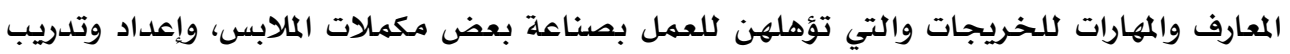

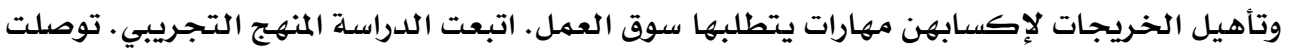

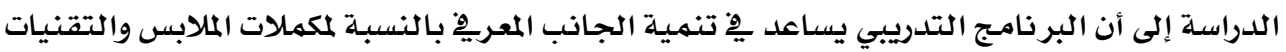

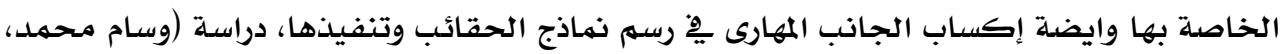

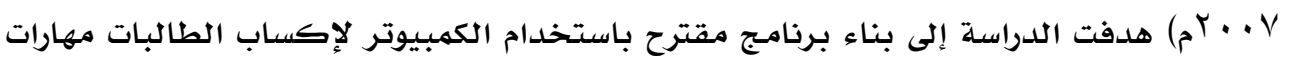

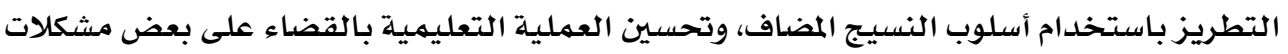

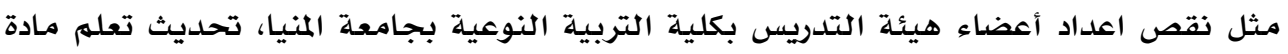

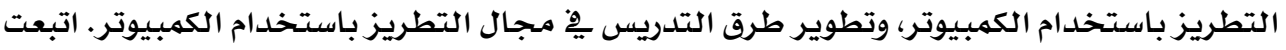

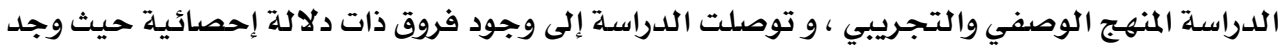

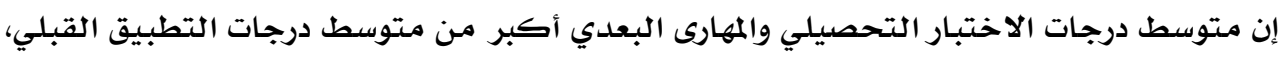

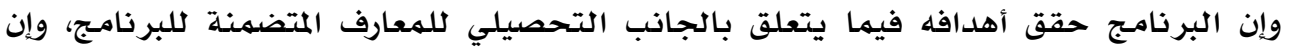

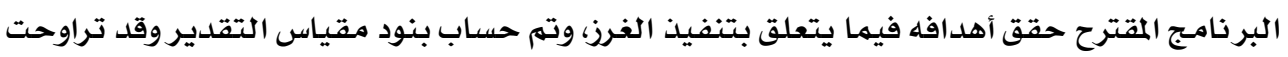

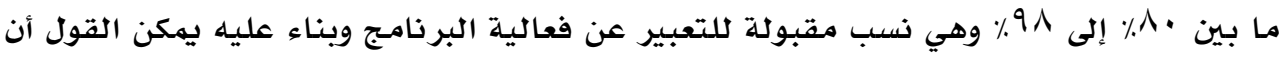

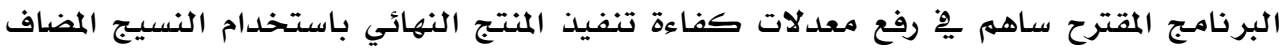

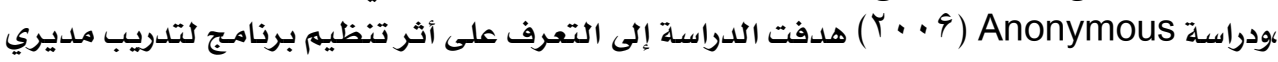

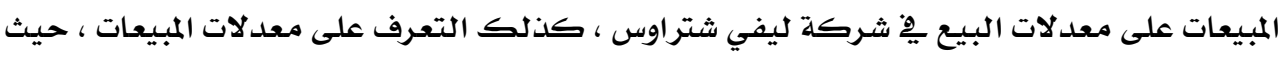

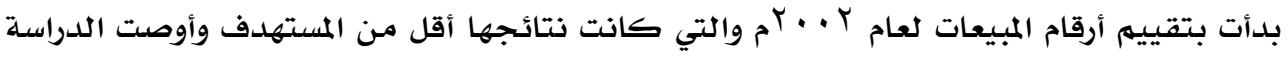

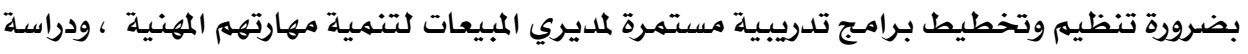
Ross Lawrence Peckford

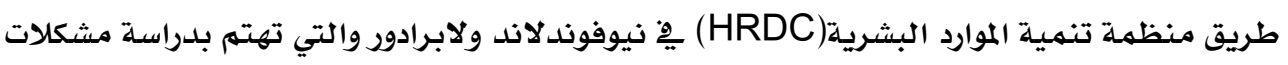

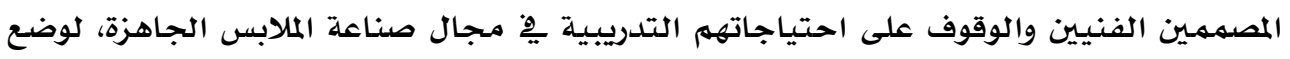
الخطوط العريضة الاستراتيجيات التدريب. التوفئين.

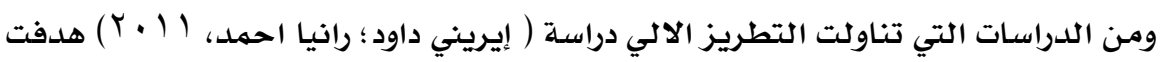

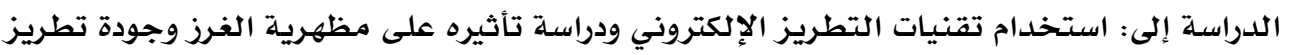

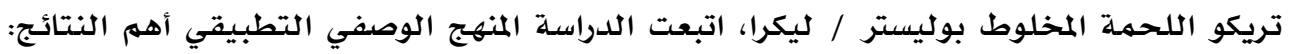

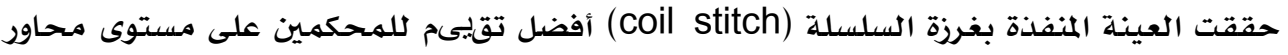


الدراسـة الثلاثة بينما حققت العينة المنفذة بغرزة الساتان (satin stitch) أقل مستوى لتقييم

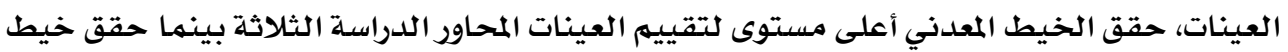

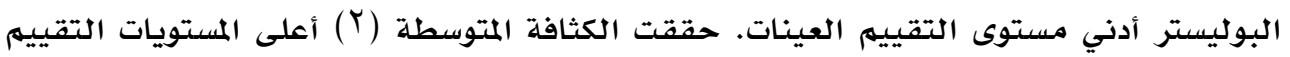

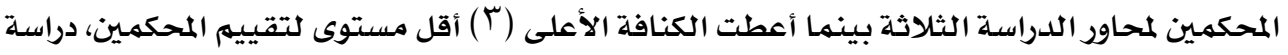

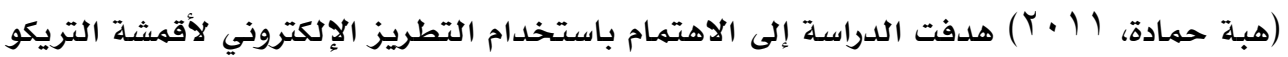

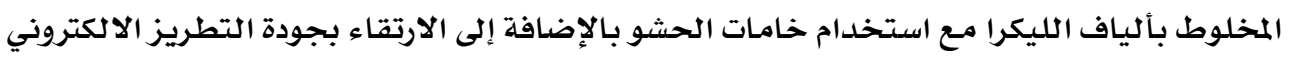

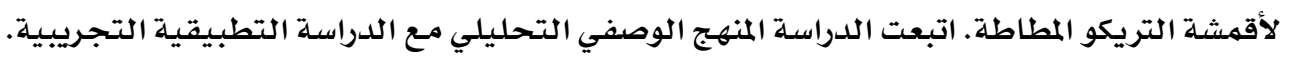

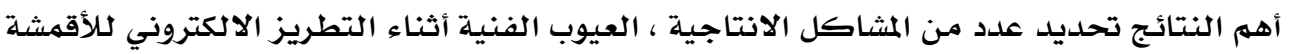

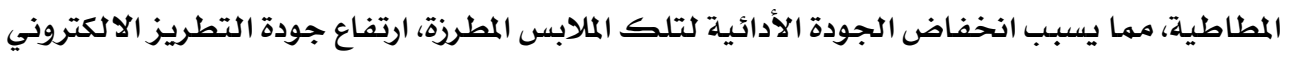

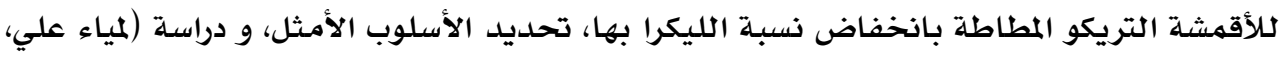

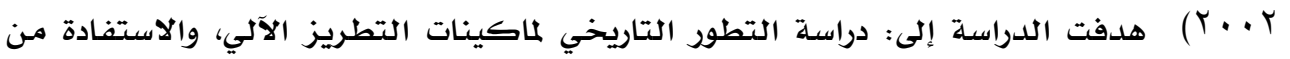

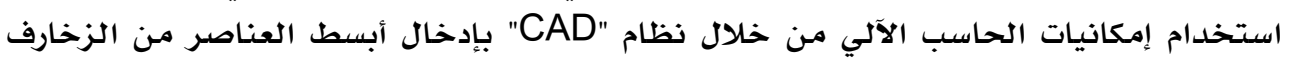

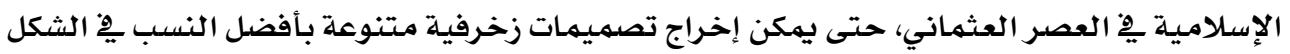

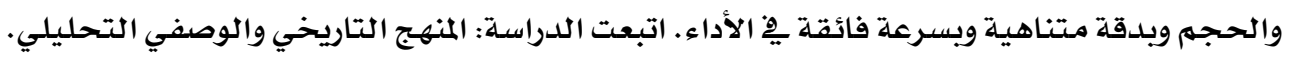

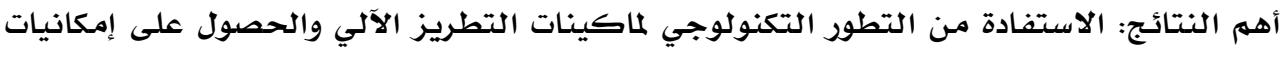

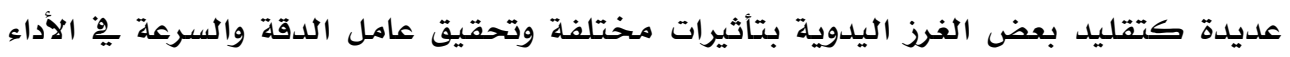

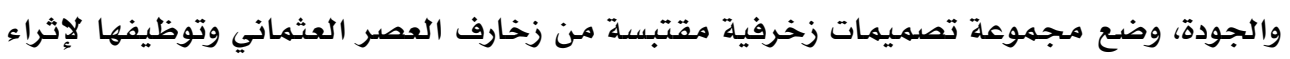

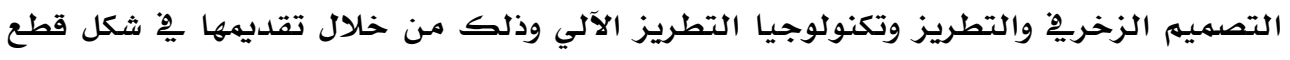

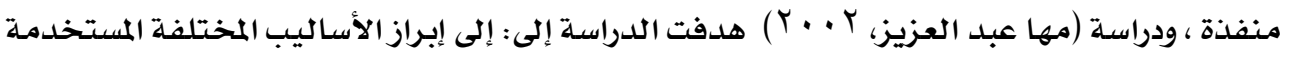

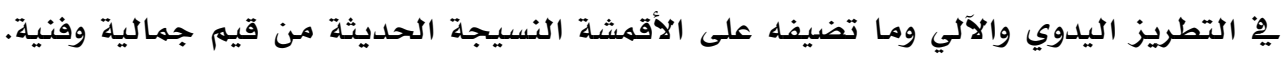

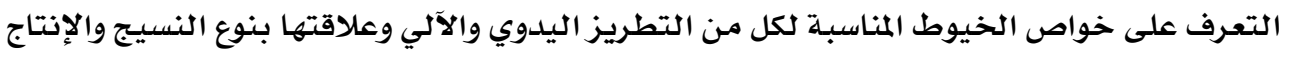

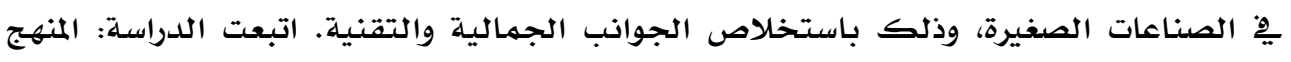

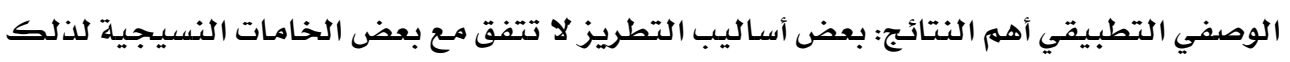

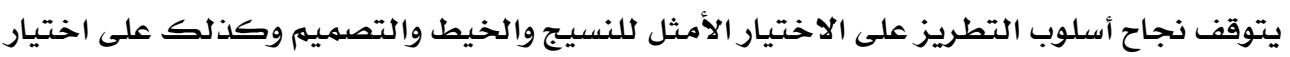

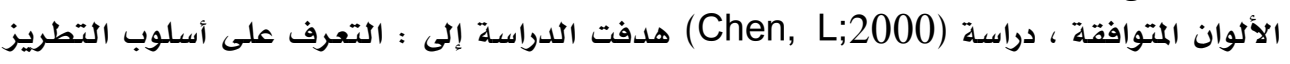

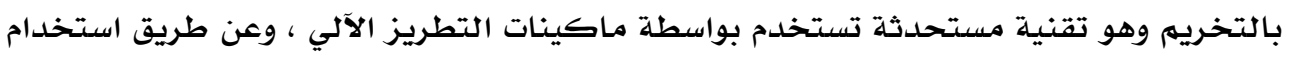

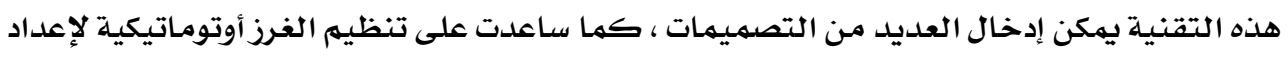

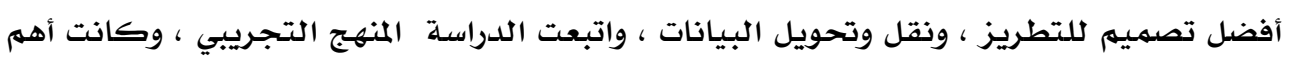

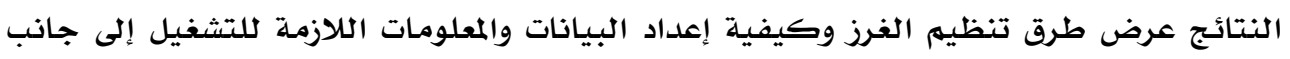


ا ـ اعداد برنامج تدريبي لتنمية مهارات التطريز الالي للخريجات لتأهيلهن لإقامسة مشروعات

$$
\text { صغيرة متوسطة. }
$$

r.بيان فاعلية البرنامج التدريبي يِّة تنمية الجوانب المعرفية يِّة التطريز الآلي للخريجات

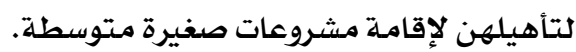

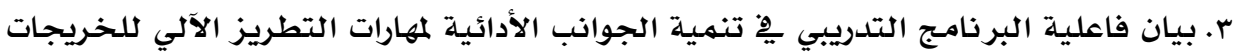

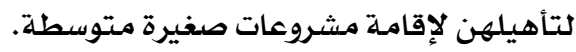

أهمينة البحث:

ا ب ابراز دور الجامعات يِّ تنمية الموارد البشرية.

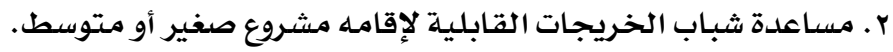

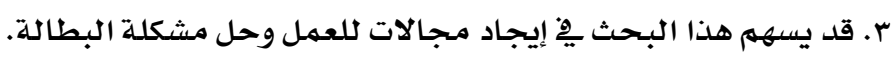

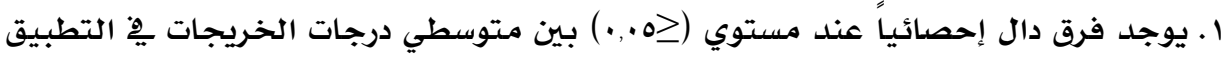

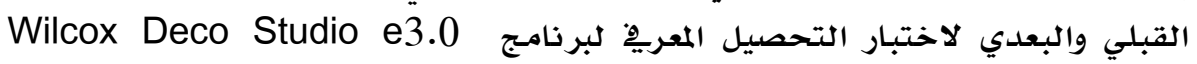

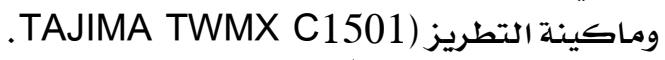

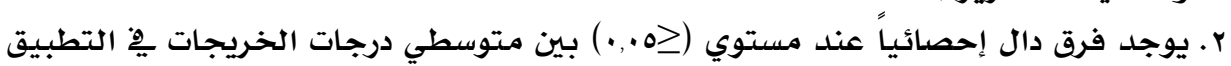

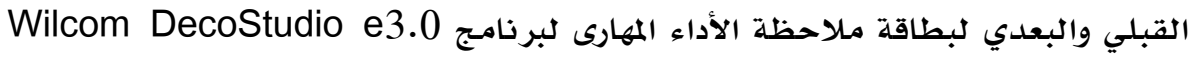

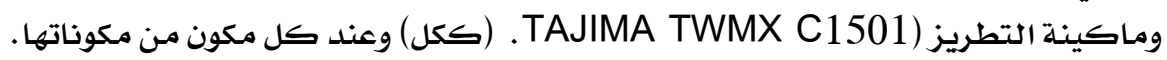

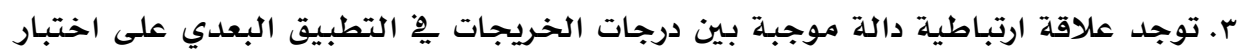

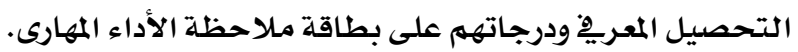

همطاحات البحث

\section{فاعلية Effectiveness:}

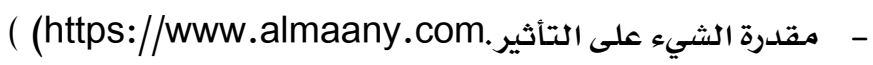
تحديد الأثر المرغوب أو المتوقع الذي يحدثه البرنامج التدريبي بغرض تحقيق الأهداف التي

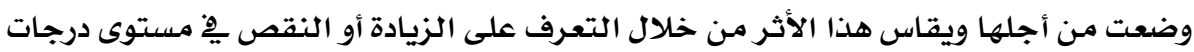

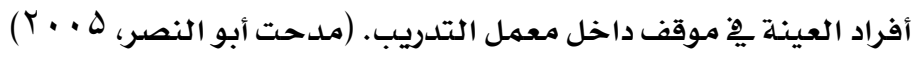

البرنامج Program

- مجموعة من الخبرات التي تعالج موضوعات متكاملة وشاملة من الناحية النظريية والعملية

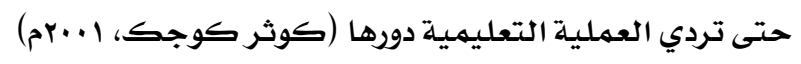




\section{التدريب Training}

تزويد الدارسين بالدراسات العملية والعلمية التي تؤدي الي رفع المهارة عندهم مِّواء أداء واجبات

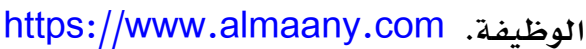

تزويد الفرد بالأساليب والخبرات والاتجاهات العملية والعلمية السلمة اللازمة لاستخدام

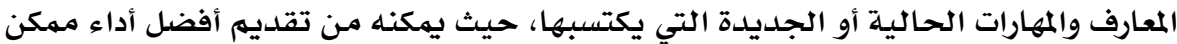

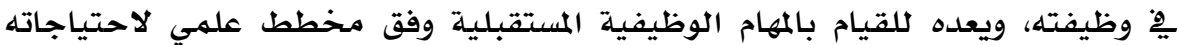

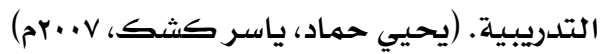

\section{البرنامجج التدريبي Training Program}

مجموعة من النشاطات المخططة والمنظمة وتتضمن بناء أو تطوير موقف تدريبي مِّ ضوء

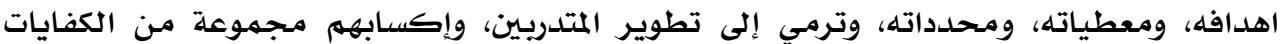

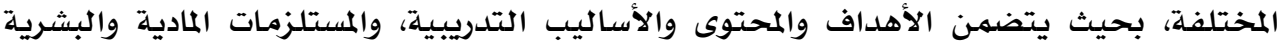

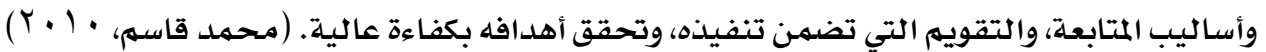
نشاط متجدد ومستمر يبدأ بالتخطيط وينتهي بالمتابعة والتقييم ويهدف إلى تطوير

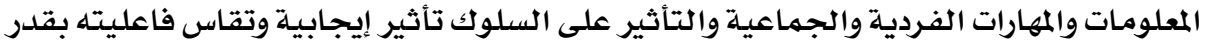

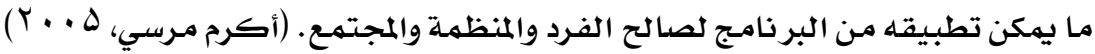
فعالية البرنامج التدريبي Effectiveness Of The Training Program: التعريف الإجرائي: قدرة البرنامـج التدريبي على تنهية مهارات التطريز الالي لدي

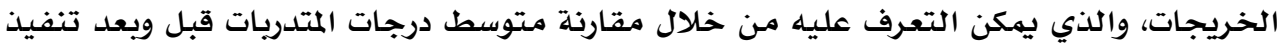
البر نامج التدريبي.

\section{مهارات Skills:}

- مجموعة من استجابات الفرد الأدائية المتناسقة التي تنمو بالتعلهم والممارسة حتى تصل الي

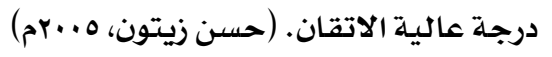

\section{التطريز الآلي: Automated Embroidery}

زخرفة القماش بواسطة ماكينة التطريز الآلي المزودة بإمكانيات تتيح عمل خطوط طولئ بولية

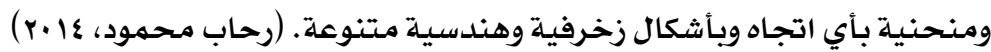

زخرفة القماش بعد نسجه بواسطة ماكينة التطريز مـع استخدام الخيوط الملونة أو بلون

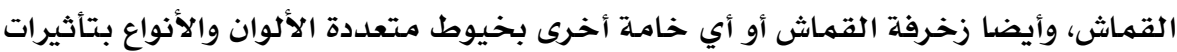

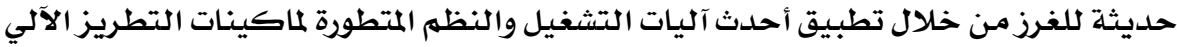

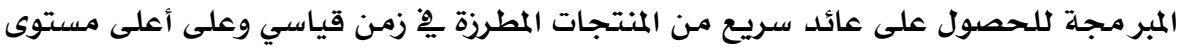

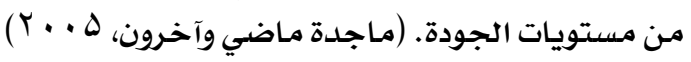


يعد برنامج Wilcom من أفضل برامج التطريز الرائدة ِِّ صناعة المنتجات المطرزة وله

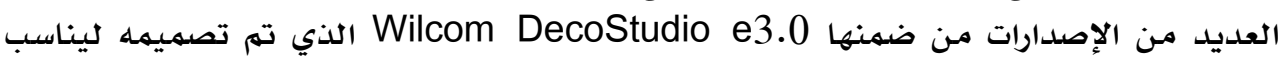

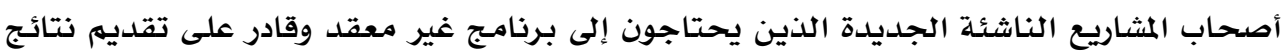

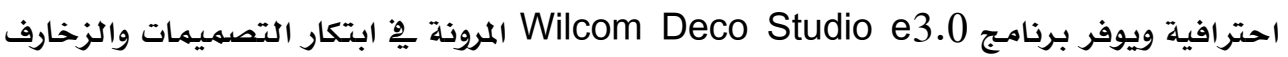

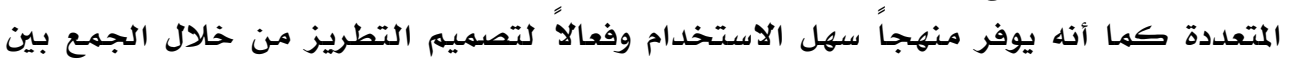

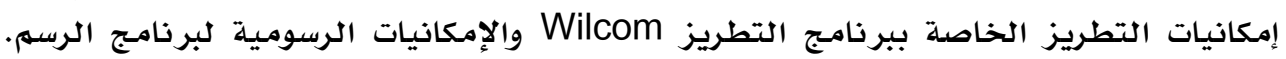

CorelDraw

يحتوي برنامج Wilcom DecoStudio e3.0 على العديد من الأيقونات والعناصر

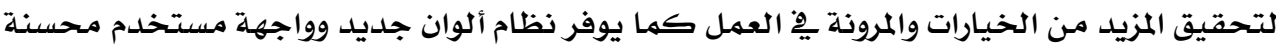

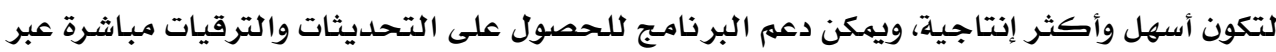
الإنترنت. (https://www.wilcom.com) ماكينة التطريز (TAJIMA TWMX C1501). (TWMX C1501) ماكينة التطريز الآلي TAJIMA TWMX C1501 تستخدم لتطريز المنتجات التي تتطلب إمكانيات تطريز عالية للجاكيتات والبلوزات الرياضية وغيرها، كما تستخدم للتطريز

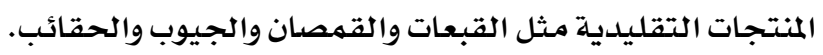

الخريجات: Graduates التعريف الاجرائي: المقصود بالخريجات بهذه الدراسة خريجات كليات الاقتصاد المنزلي بمجال الملابس والنسيج.

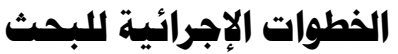

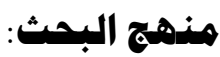

المنهج الوصفي لتحديد تقنيات التطريز الآلي بالبرنامج التدريبي لتنمية مهارات

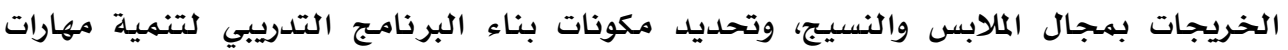

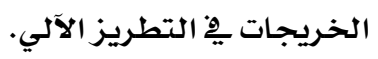

المنهج التجريبي لقياس فاعلية البرنامـج التدريبي يِّ تنمية مهارات الخريجات بمجال

$$
\text { أدوات البملابس والنسيج ِِّ التطريز الآلي. }
$$

أ. برنامجج تدريبي لتنمية مهارات الخريجات يِ التطريز الآلي.

ب. بطاقة ملاحظة لتقويم مـراحل تطبيق البرنامـج التدريبي. 
مجلة بحوث التربية النوعية - علد ov - م.r. - ميناير

$$
\text { عينة البحث: اختبار تحصيلي لتقويم الجانب المعريٌ للبر نامج التدريبي. }
$$

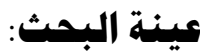

اشتملت عينة البحث على ما يلي:

ا ـ المجال المكاني: طبقت هذه الدراسلة ِِّ كلية التصاميهم بجامعة القصيم وذلك للأسباب

التالية:

Wilcom DecoStudio e3.0 لتوفر برنامـ - ل لتوفر ماكينة التطريز الآلي (TAJIMA TWMX C1501) فيها. r . المجال البشري: عينة قصديه وعمدهن (Y0) وتتوافر بهن الاتي: - ألا يقل عمر المتدرية عن r r ع عامLاً.

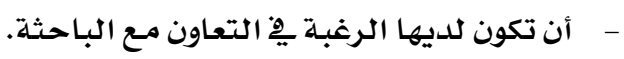

- - ان تكون من خريجات كليات الاقتصاد المنزلي تخصص الملابس والنسيج

- أن تحصل على درجات متدنية على مقياس مهارة التطريز الالي.

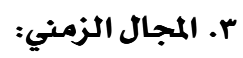

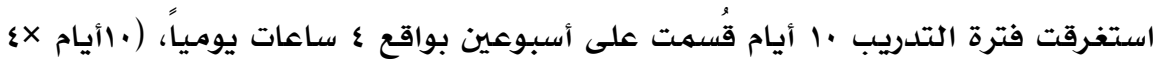

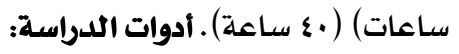

$$
\begin{aligned}
& \text { - برنامـج تدريبي } \\
& \text { - بطاقة ملاحظة } \\
& \text { - اختبار تحصيلي }
\end{aligned}
$$

\section{إجراsات البحث: أبحث:}

أولا: اعداد البرنامج التدريبي:

قامت الباحثة بإعداد وبناء البرنامـج التدريبي لتتمية مهارات الخريجات بمجال الملابس

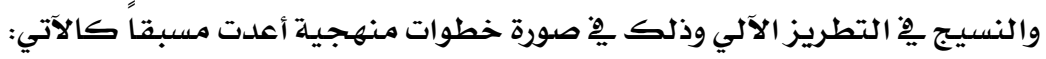

ا ـ تحديد موضوع البرنامـج: برنامـج تدريبي لتنمية مهارات الخريجات يِّ التطريز الآلي بمدال

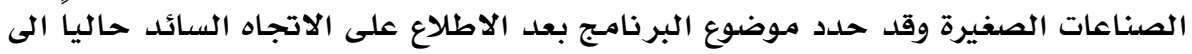

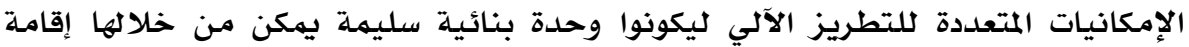
صناعات صغيرة يْ مجال التطريز 


$$
\text { r. تحديد أهداف البرنامج: }
$$

أولاً : الأهداف العامة للبرنامـج: تنمية مهارات الخريجات بِّ التطريز الآلي، وقدرتهن على إنتاج

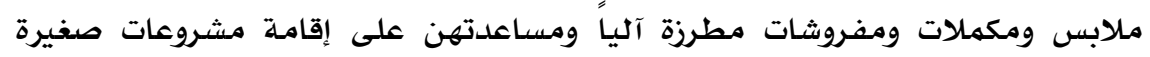

$$
\text { ثانياً : الأهداف الإجرائية للبرنامـج: }
$$

أ. الأهداف المعرفية: التي تهتم بالمعلومات والحقائق:

أ- الأهداف التفصيلية للبرنامج (الأهداف النفس حركية)

تستطيع المتدريسة بعد انتهاء فترة التدريب واجتيازها للبر نامـج التدريبي أن:

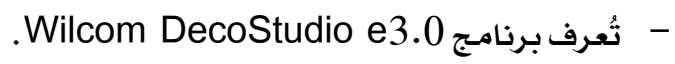

- تُعدد احتياطات السلامـة التي يجب مراعاتها عند تشغيل ماكينة التطريز (TAJIMA

(TWMX C1501

- تشرح أجزاء ماكينة التطريز (TAJIMA TWMX C1501).

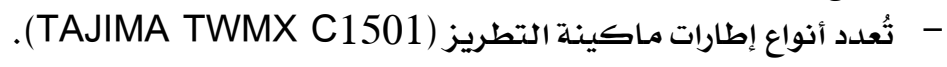

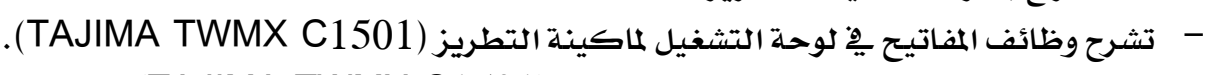

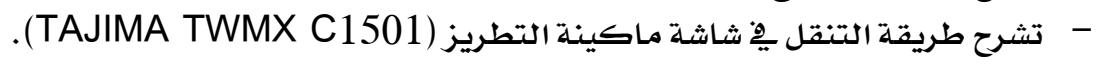
- تشرح تفاصيل الشاشة الرئيسية لماكينة التطريز (TAJIMA TWMX C1501) الأهداف المهارية: التي تهتم باكتساب المهارات:

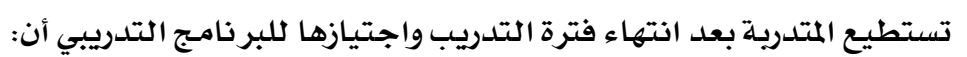

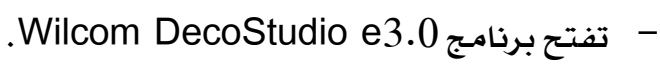

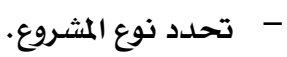
- - تحدد نوع الخامـة المراد تطريزها.

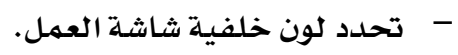
- - تضبط شاشلة المعايرة.

- - ترسم الجزء المطلوب من خلال أيقونة تعبئة الانصهار.

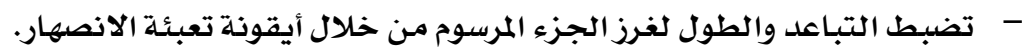
- - تختار غرزة التعبئة للجزيء المرسوم من خلاعلال أيقونة تعبئة الانصهار.

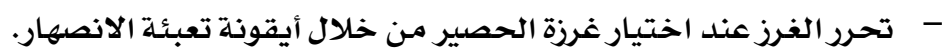

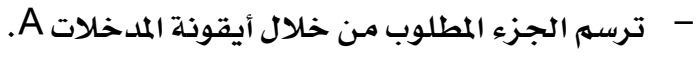

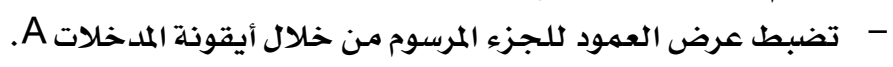

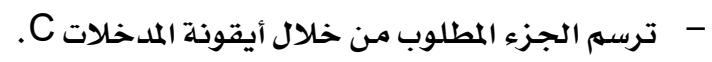

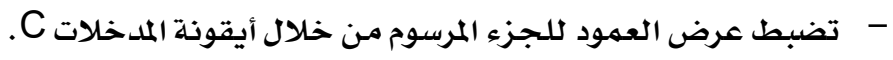

\section{4.}




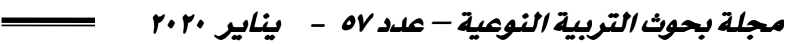

- ترسم خط متصل سواء مستقيم أو منكسر أو منحني من خلال أيقونة تشغيل.

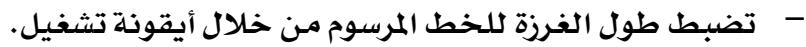

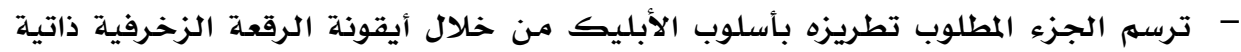
الحركة.

تطرز كلمـات أو نصوص باللغلة الإنجليزية من خلال أيقونة عمل أحرف.

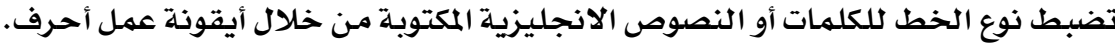

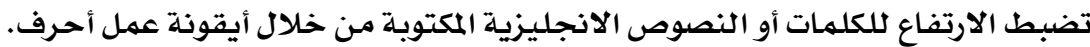

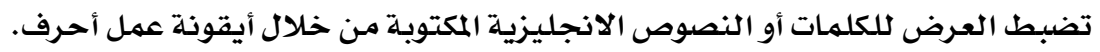

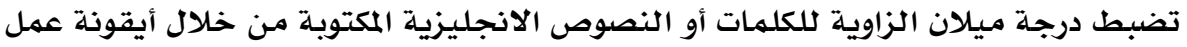
أحرف. تضبط المسافة بين الحروف للكلمات أو النصوص الانجليزية المكتوبة من خلال أيقونة عمل أحرف.

تضبط المسافة بين الكلمات للنصوص الانجليزية المكتوبة من خلال أيقونة عمل أحرف.

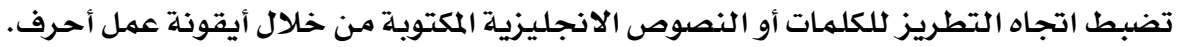

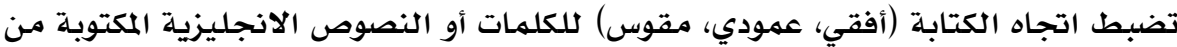
خلال أيقونة عمل أحرف.

تطرز حروف أو كلمات داخل إطارات ونقوش موجودة مسبقاً بالبرنامج أو موجودة ـيف

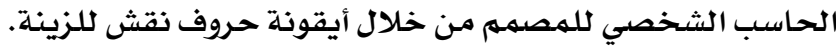

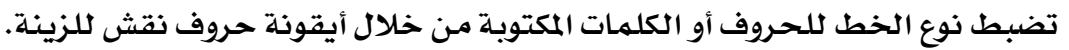

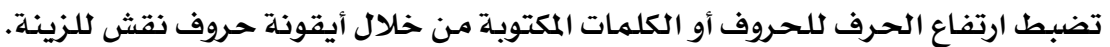
تضبط درجة التدوير للحروف أو الكلمات المكتوبة من خلال أيقونة حروف نقش للزينة. تضبط لون الحرف للحروف أو الكلمات المكتوبة من خلال أيقونة حروف نقش للزينـة. تضيف الحلي من خلال أيقونة حروف نقش للزينة.

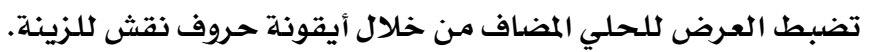

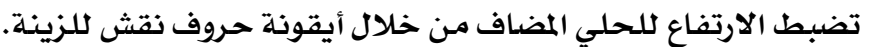
تضبط درجة التدوير للحلي المضاف من خلال أيقونة حروف نقث للزينـة.

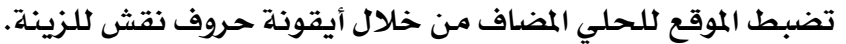

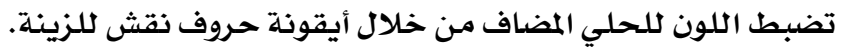

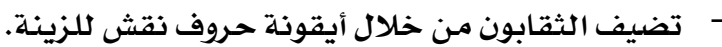

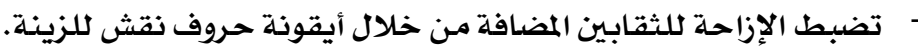
- مضبط نسبة العرض إلى الارتفاع للثقابين المضافة من خلال أيقونة حروف نقش للزينة.

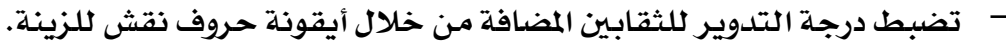
- تضبط نوع غرز الخطوط العريضة للثقابين المضافة من خلال أيقونة حروف نقش للزينـة. 
- - تضبط نوع غرز التعبئة للثقابين المضافة من خلال أيقونة حروف نقث للزينة.

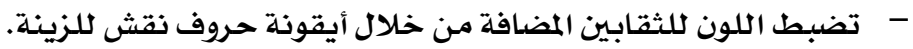

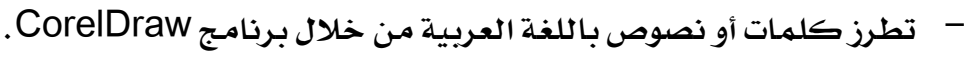

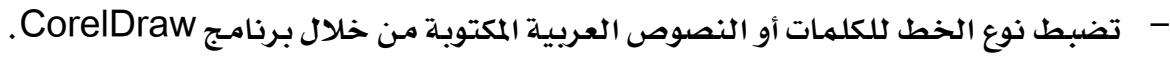

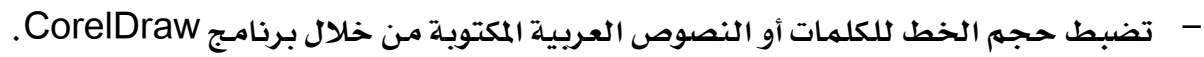

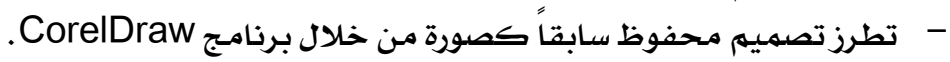

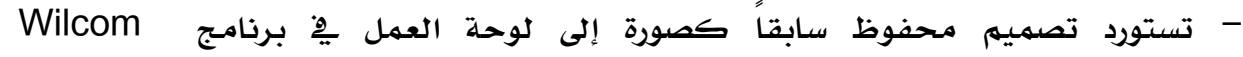

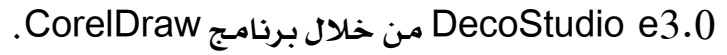
تحدد التصميم أو جزء منه لتتمكن من (تحريكه أو تكراره أو حذفه أو تغيير لونه أو ضبط خصائصده) من خلال أيقونة اختيار جزءء. تعدل نقاط الجزء المرسوم (بتحريكها أو إضافتها أو حذفها منها أو تحويلها من نقاط مستونة مستقيمة

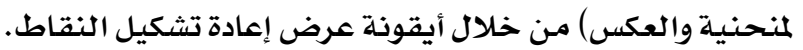

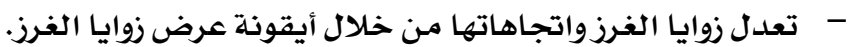

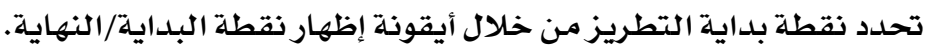

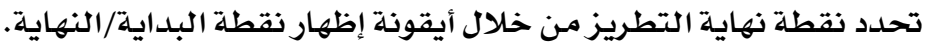
تحرروتحذف الغرز عند اختيار غرزة الستان من خلال أيقونة تحرير الغرزات.

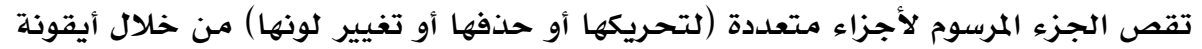
السكين. تعكس الجزء المرسوم (أفقياً أو عمودياً) .

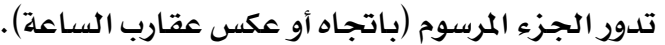

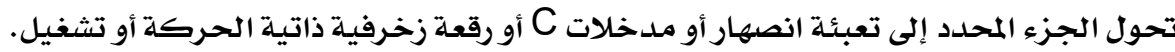

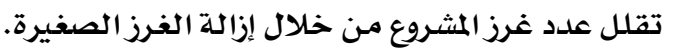

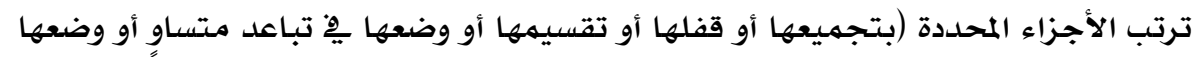

$$
\text { تعاين المشروع قبل تطياس). }
$$

تحفظ المشروع بصيغة تلدعم التعديل عليه لاحقا.

$$
\text { تحفظ المشروع بصيغة ماكينة التطريز الآلي. }
$$

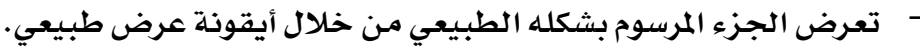

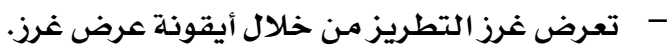

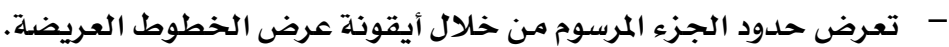
- - تعرض نقاط الإبر من خلال أيقونة عرض نقاط الإبر.

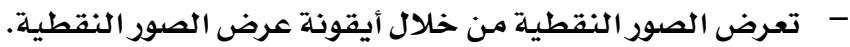

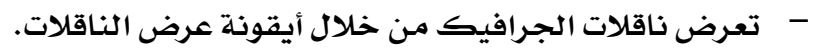




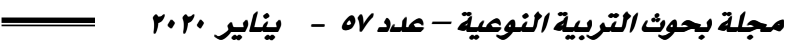

- - تعرض تصميمات النسيج من خلال أيقونة عرض نسيج الرقعة الزخرفية.

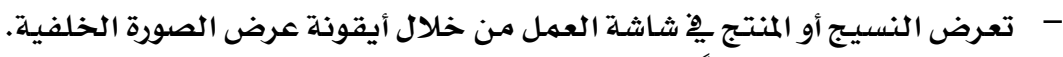

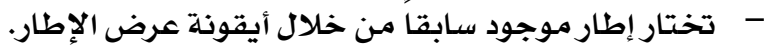

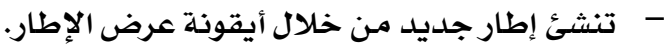
- تعرض شبكة يِّ لوحة العمل من خلال أيقونة عرض الشبكة.

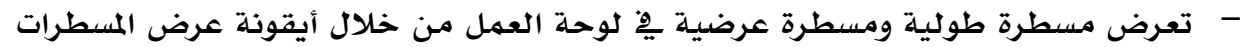

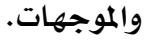

تختار وحدة القياس بِّ البر نامج من خلال أيقونة نظام قياس التصميهم.

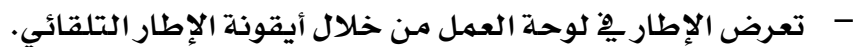

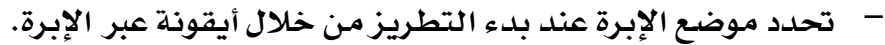
- - تشغل محاكاة لخطوات ومـراحل التطريز من خلال أيقونة إعادة رسمى بطيئة. - - تضبط خصائص الجزء المحلدد من خلادل أيقونة خصائص التص الكائنات.

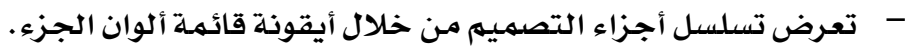

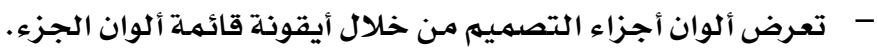

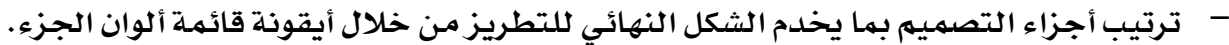

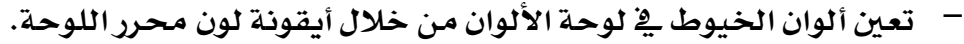

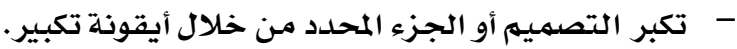

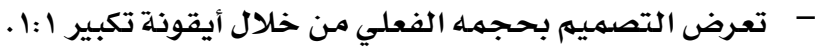
- - تحدد نسبة التكبير من خلال أيقونة عامل التكبير.

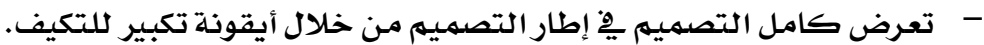
- - - تكبر الجزء المحلدد من خلال أيقونة تكبير إلى الاختيار.

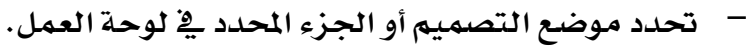

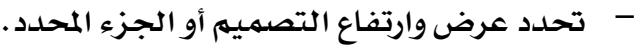

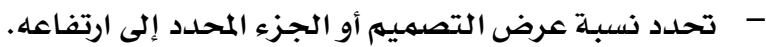

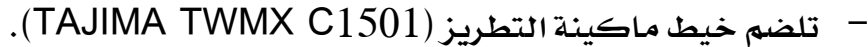

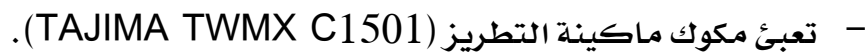

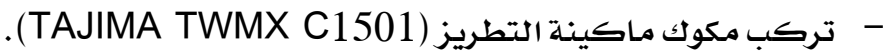
- ت تثبت النسيج بِِّ الإطار. - توصل ماكينة التطريز (TAJIMA TWMX C1501) بالتيار الكهريائي. - تشغل ماكينة التطريز (TAJIMA TWMX C1501).

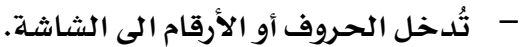

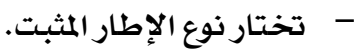


- تختار التصميم المراد تطريزه مـن ذاكرة (USB).

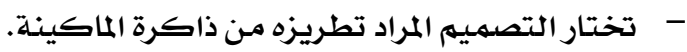

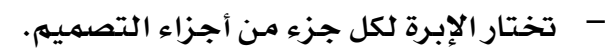

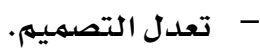
- ت تكرر التصميه.

- تغير لون خيط الإبرة ِيْ الماكينة. - تطّلع على تقرير التصميم الذي يتهم تطريزه. - - تنقل التصميهم من مكان لآخر.

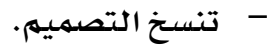
- ت تغير اسهم التصميه.

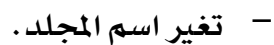
- تفرز التصاميهم مِّْ ذاطرة الماكينة.

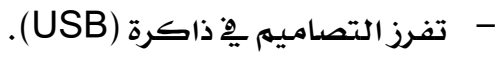

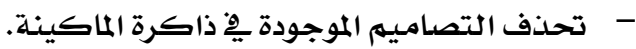
- - توقف تشغيل ماكينة التطريز الآلي (TAJIMA TWMX C1501). - ت تنفذ عينات مطرزة آلياً باستخدام ماكينة التطريز الآلي (TAJIMA TWMX C1501). ج. الأهداف الوجدانية:

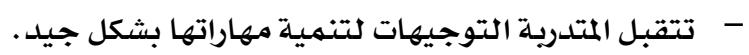

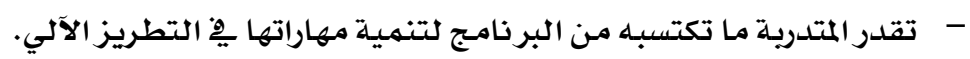

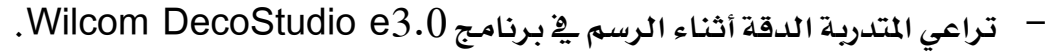

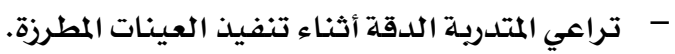

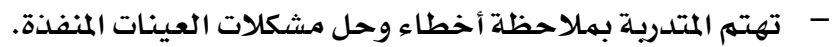

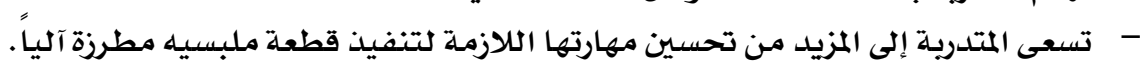
r. تحديد محتوي البرنامج التدريبي: يأتي تحديد محتوى البرنامج كخطوة تالية لمرحلة

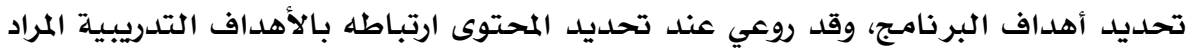

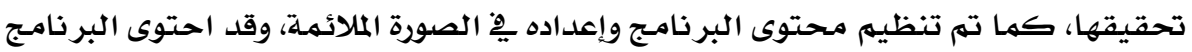

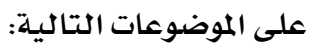

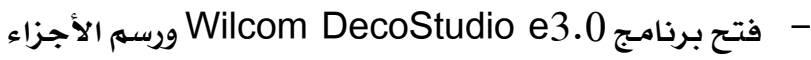

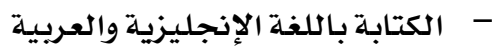

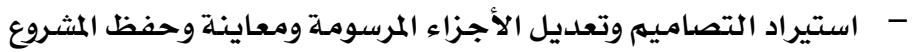

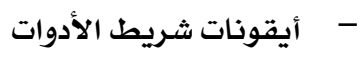
- - 


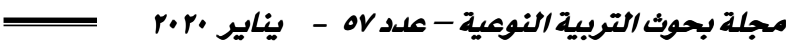

$$
\text { ع. الأساليب التدريبية للبرنامج }
$$

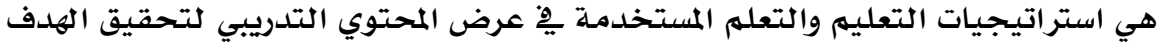
منسه ويتم اختياره وفقا لما يلي:

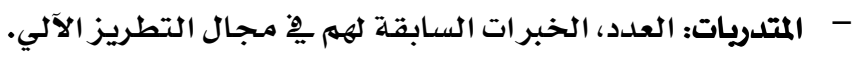

$$
\begin{aligned}
& \text { - ظروف التدريب: زمن التدريب، المكان، الأدوات والوسائل المساعدة للبر نامجـ. } \\
& \text { - المحتوي التدريبي: مراعاة مستوي موضوع التدريب عند اختيار الأساليب التدريبية. } \\
& \text { - - المدرب: مدي اتقانه للأساليب التدريبية المختلفة. }
\end{aligned}
$$

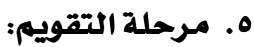

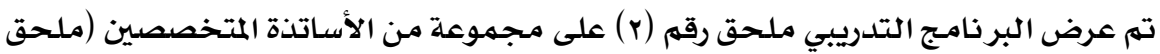

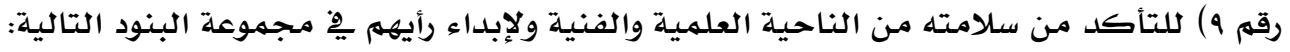

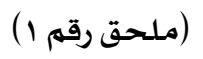

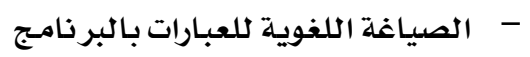

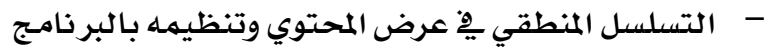

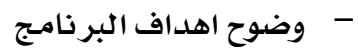

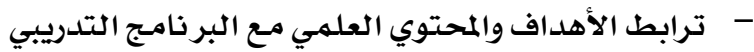

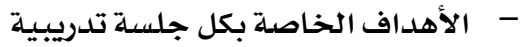

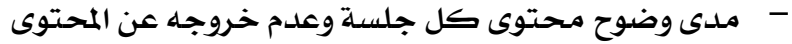

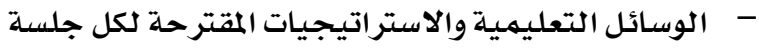

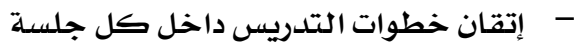

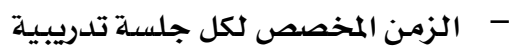

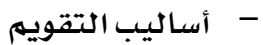

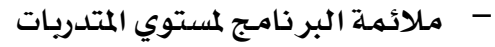

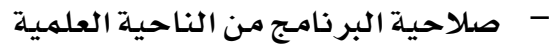

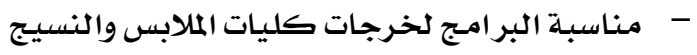

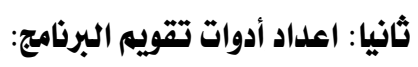

| - 1 بطاقة ملاحظة

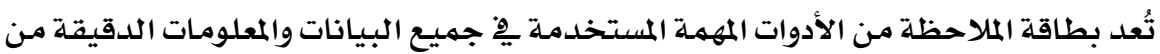

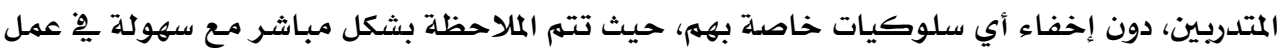
تقويم مستمر. 
تم اعداد بطاقة ملاحظة (ملحق رقم ع) وعرضها على مجموعة من الأساتذة المتخصصين

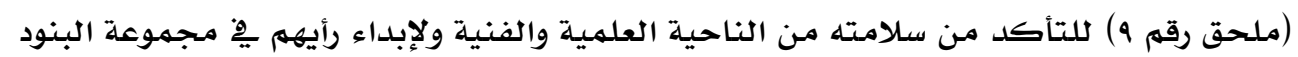

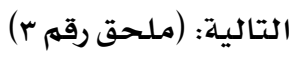

$$
\begin{aligned}
& \text { - } \\
& \text { - } \\
& \text { - }
\end{aligned}
$$

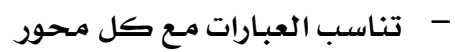

$$
\begin{aligned}
& \text { - - } \\
& \text { - - - سهولة ووضوح العبارات }
\end{aligned}
$$

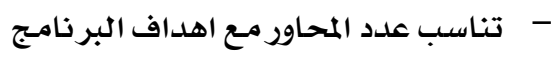

$$
\begin{aligned}
& \text { r. الاختبار التحصيلي: }
\end{aligned}
$$

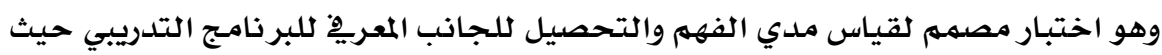

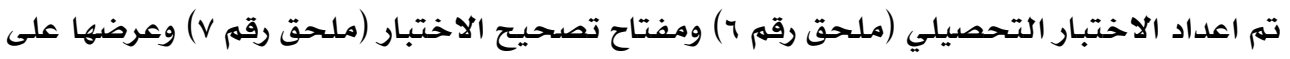

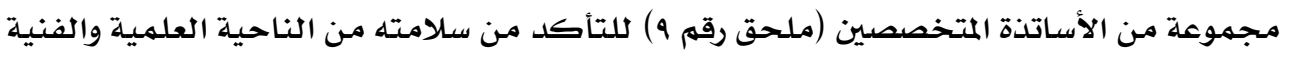

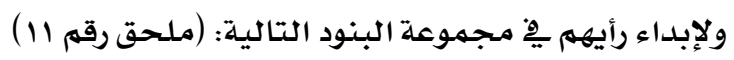

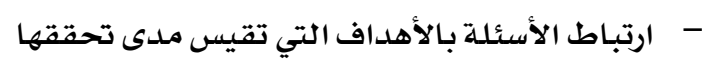

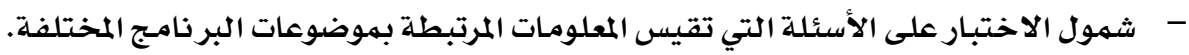

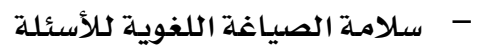

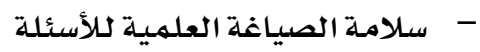

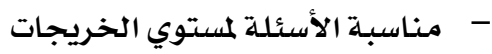

$$
\begin{aligned}
& \text { تقنيز الأدوات (الصدة والثبات): }
\end{aligned}
$$

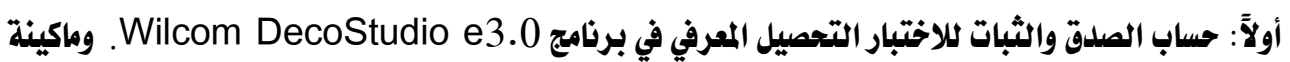

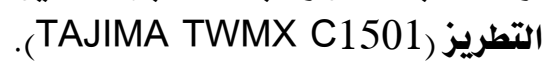

$$
\text { أولاً: ضبط الاختبار التحصيلي (التبري }
$$

تحديد صدق الاختبار وذلك بطريقتين:

أ أ الصدق الظاهري:

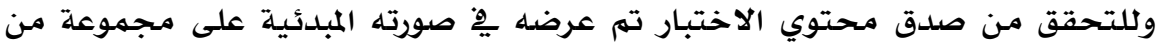

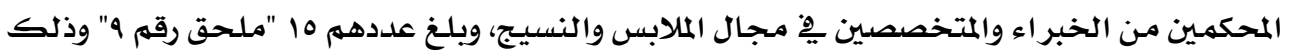

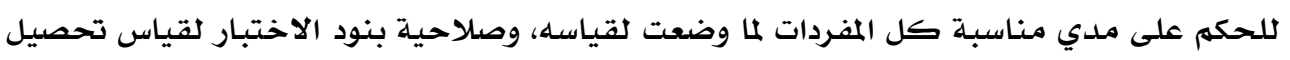

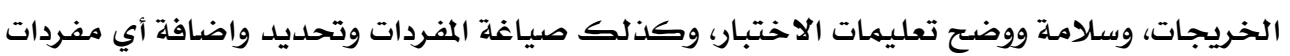

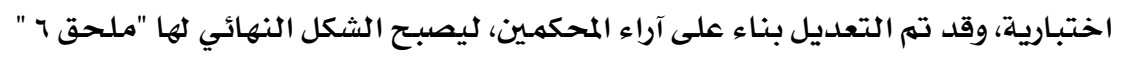


ب. حساب صدق الاتساق الداخلي:

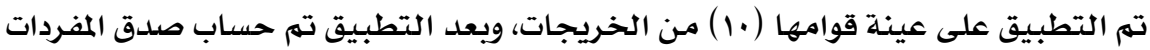
بطريقة معامل ألفا دـ كرونباخ Alpha Cronbach (حساب الثبات الكلي وصدق التبق المفردات) وهو

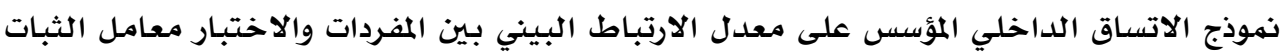

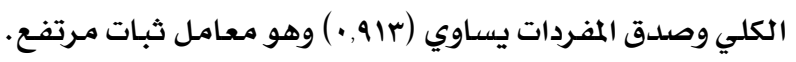

اختبار ثبات الاختبار التحصيلي

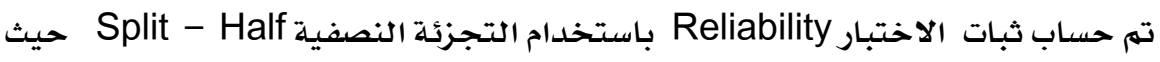

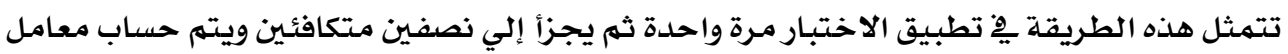

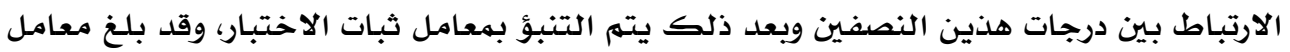

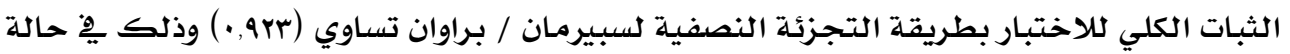

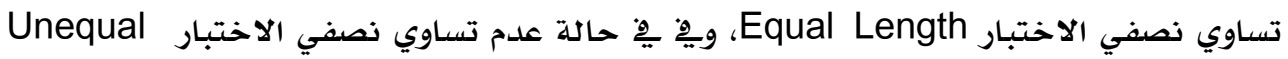

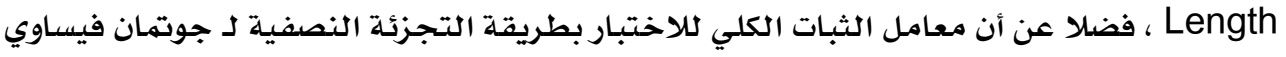

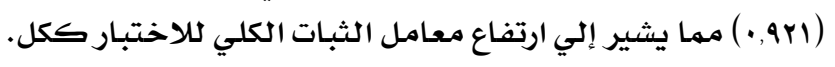
حساب زمن الاختبار التحصيلي

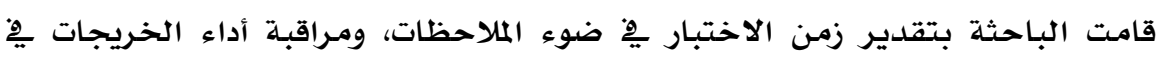

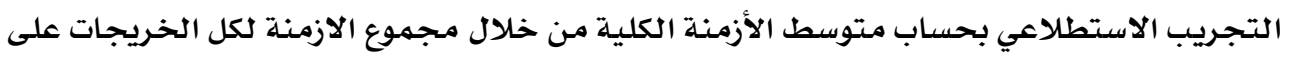

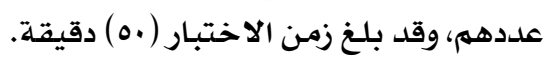
حساب معاملات السهولة والصعوبة لمفردات الاختبار التحصيلي

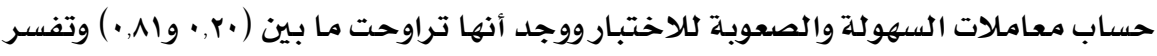
بأنها ليست شديدة السهولة أو شديدة الصعوبة، وبالتالي ظل الاختبار بهفرداته كما هو هو ( ـه ) مفردة. حساب معامل التمييز لمفردات الاختبار التحصيلي تم حساب معاملات التميز للاختبار وبذلك تعتبر مفردات الاختبار ذات قدرة مناسبة للتمييز.

وضع الاختبار التحصيلي ـِ الصورة النهائية للتطبيق

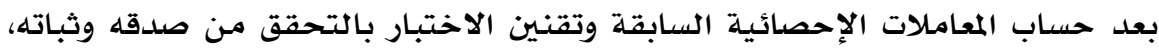

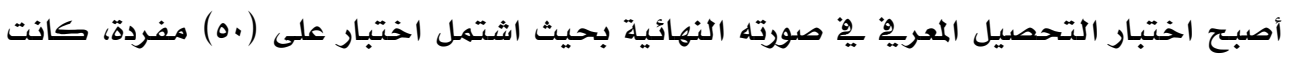

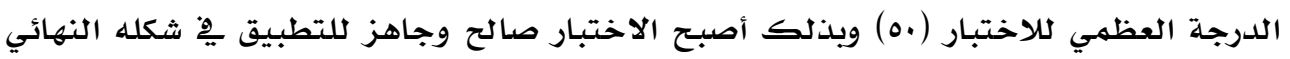

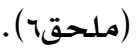


قامت الباحثة بدراسـة بعض الأدبيات والدراسات السابقة المتعلقة بالمتغيرات التابعة للبحث لاستخلاص الأداء المهارى المرتبط ببرنامج ل3:0

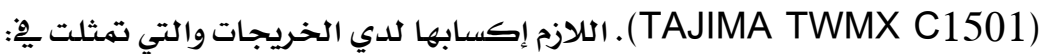

$$
\begin{aligned}
& \text { 1. فتتح البر نامجج ورسم الأجزاء وتضمنت (17 ) مؤشر }
\end{aligned}
$$

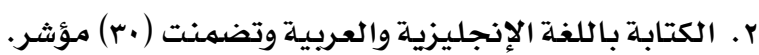

r. استيراد التصاميم وتعديل الأجزاء المرسومة ومعاينة وحفظ المشروع وتضمنت (IV) مؤشر.

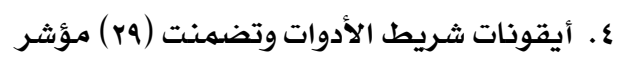

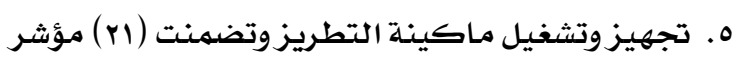

وتم ملاحظة عينة استطلاعية أثناء التجريب الاستطلاعي وتسجيل مواقفهم وتحليلها،

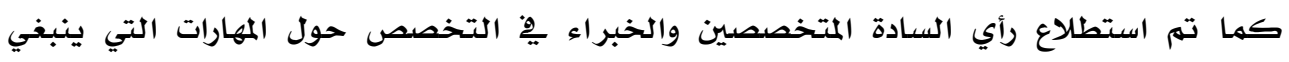

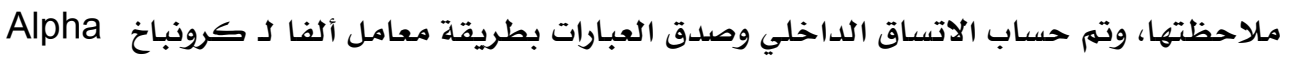

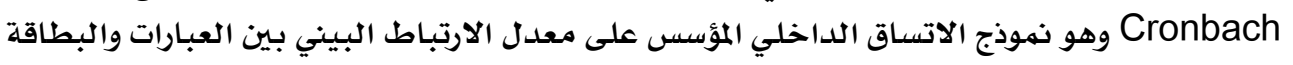

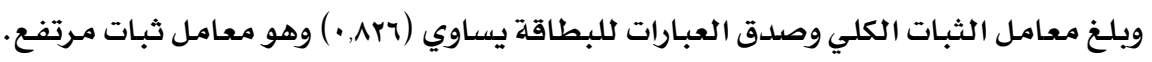

اختبار ثبات بطاقة ملاحظة الأداء المهارى

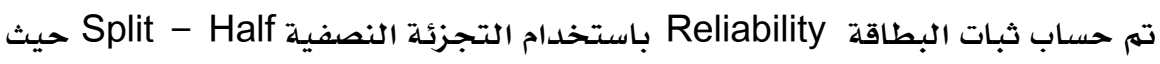

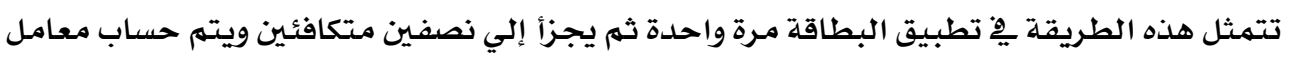

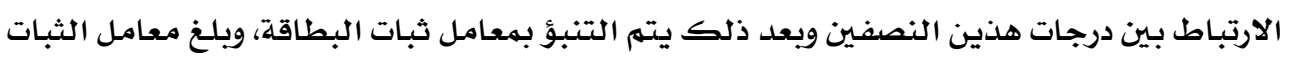

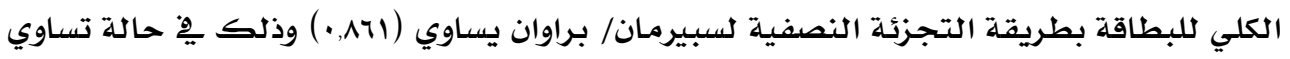

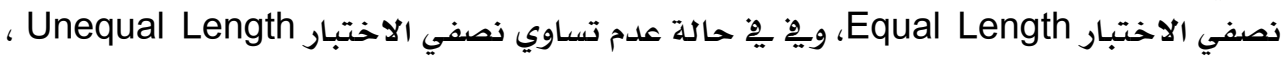

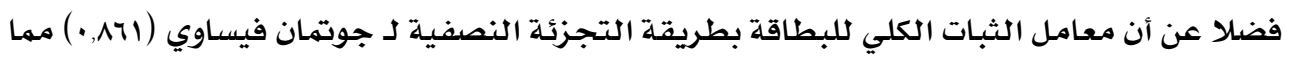

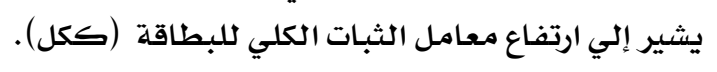

\section{حساب زمن بطاقة ملاحظة الأداء الأداء المهارى.}

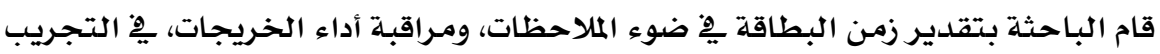

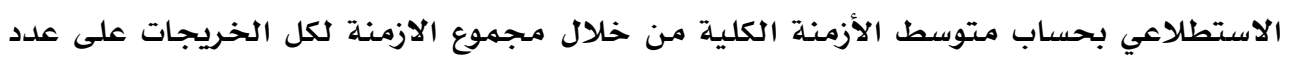

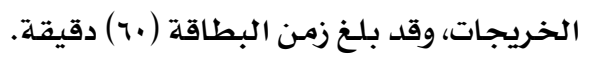




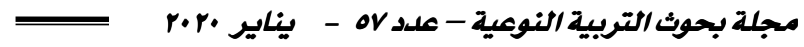

حساب معاملات السهولة والصعوبة لمفردات بطاقة ملاحظة الأذاء المهارى.

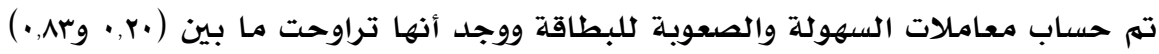

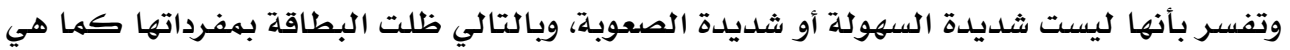

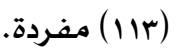

حساب معامل التمييز لمفردات بطاقة ملاحظة الأداء المهارى.

تم حساب معاملات التميز للبطاقة وتراوحت ما بين (·ץ, • وایی,·) وبذلك تعتبر مفردات

البطاقة ذات قدرة مناسبة للتمييز.

وضع بطاقة ملاحظة الأداء المهارى ِِِ الصورة النهائية للتطبيق

بعد حساب المعاملات الإحصائية، أصبحت بطاقة ملاحظة الأداء المهارى يّْ صورتها النهائية

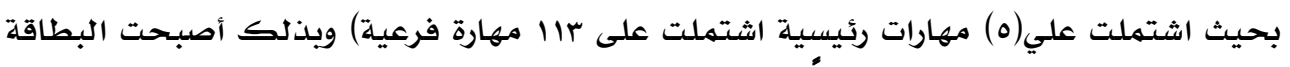

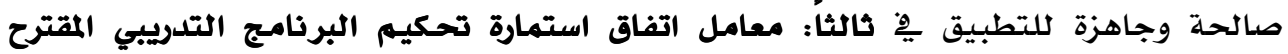
للخريجات بمجال الملابس والنسيج

قامت الباحثة بحساب معامل اتفاق السـادة المتخصصين ِِّ البر امـج التكنولوجية على بنود

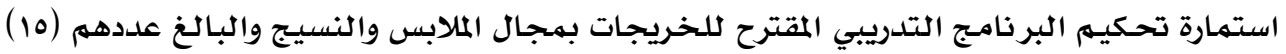

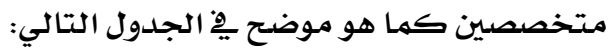

جدول (1) معامل اتفاق استمارة تحكيم البرنامج التدريبي المقترح للخريجات بمجال الملابس والنسيج شكلها

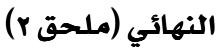

\begin{tabular}{|c|c|c|c|}
\hline معامل الاتفاق & علدد مرات علدم الاتفاق & علدد مرات الاتفاق & بنود التحكيم \\
\hline $86.66 \%$ & 2 & 13 & الصياغة اللفوية للعبارات بالبرنامج \\
\hline $80 \%$ & 3 & 12 & التسلسل المنطقي في عرض المحتوي وتنظيمه بالبرنامج \\
\hline $80 \%$ & 3 & 12 & وضوح اهداف البرنامج \\
\hline $93.33 \%$ & 1 & 14 & ترابط الأهداف والمحتوي العلمي مع البرنامج التدريبي \\
\hline $90 \%$ & 0 & 15 & الأهداف الخاصة بكل جلسة تدريبية \\
\hline $93.33 \%$ & 1 & 14 & مدى وضوح محتوى كل جلسة وعلدم خروجه عن المحتوى. \\
\hline $93.33 \%$ & 1 & 14 & الوسائل التعليمية والاستراتيجيات المقترحة لكل جلسة \\
\hline $100 \%$ & 0 & 15 & إتقان خطوات التدريس داخل كل جلسة. \\
\hline $93.33 \%$ & 1 & 14 & الزمن المخصص لكل جلسة تدريبية. \\
\hline $100 \%$ & 0 & 15 & أساليب التقويم. \\
\hline $93.33 \%$ & 1 & 14 & ملائمة البرذامج الستوي المتدربات \\
\hline $100 \%$ & 0 & 15 & صلاحية البرنامج من الناحية العلمية \\
\hline $93.33 \%$ & 1 & 14 & مناسبة الببرامج لخرجات كليات الملابس والنسيج \\
\hline
\end{tabular}


استخدمت الباحثة طريقة اتفاق المتخصصين البالغ عددهم (10) يِّ حساب ثبات الملاحظين كتحديد بنود التحكيم التي يتم تنفيذها بشرط أن يسجل كل منهم ملاحظاته مستقلا عن الأخر،

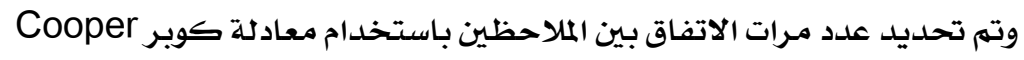
نسبة الاتفاق= (عدد مرات الاتفاق / (عدد مرات الاتفاق + عدد مـرات عدم الاتفاق)) × ...

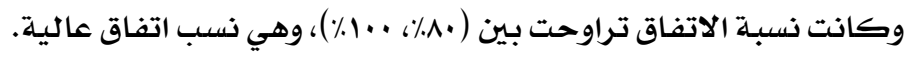
ك) تطبيق البرنامج:

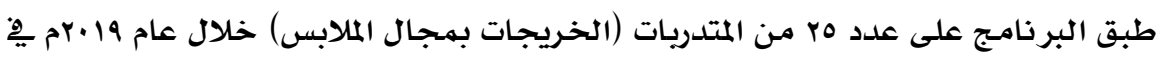

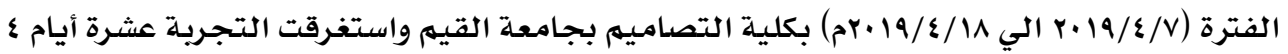

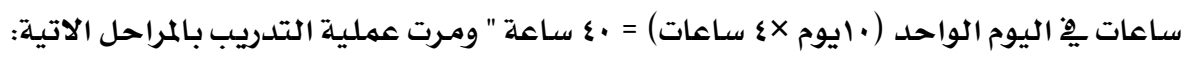
تجهيز مكان التدريب: - قامت الباحثة من التأكد من تجهيز مكان التدريب واستيعابه لعدد المتدريات وملاءمة المكان للتدريب. - تم عرض توضيحي على شاشـة عرض للتعريف بعنوان واهداف ومحتوي البر نامج التدريبي مرحلة ما قبل التدريب أولا: الاختبار القبلي كلاختبار التحصيلي: طبق يِّ اليوم الأول للتجربة الاختبار التحصيلي القبلي حيث طلب من كل متلدرب

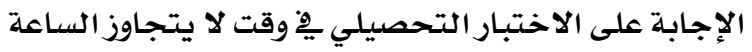
مرحلة التدريب (تطبيق البرنامج) - تم تنفيذ محتوي البرنامج على جلسات كل جلسة ؛ ساعات لمدة م أيام متصلة ماعدا يومي الجمعحة والسبت.

- توزيع حقيبة تدريبية على كل متدرية للرجوع لها وقت الحاجة.

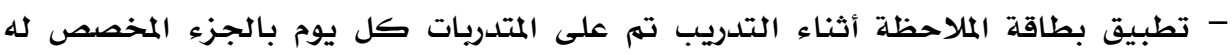

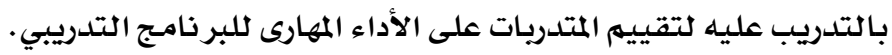

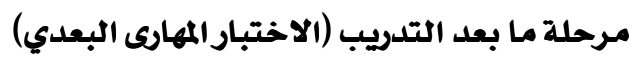
بعد الانتهاء من دراسة البرنامج طلب من كل متدرب الإجابة على الاختبار التحصيلي.

نتائج البحث ومهناقشتهها:

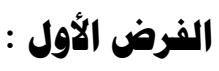

للتحقق من صحة الفرض الأول من فروض البحث والذي ينص علي: " يوجد فرق دال

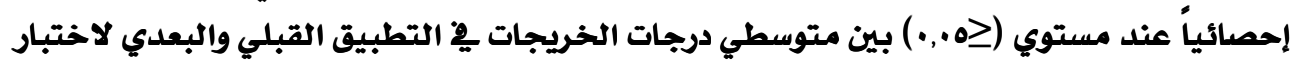




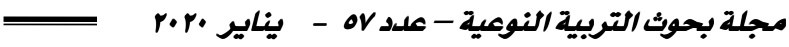

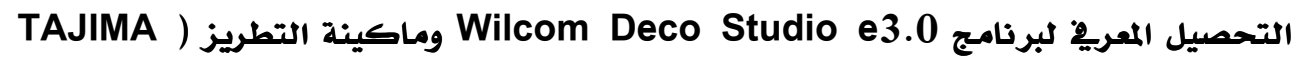

.TWMX C1501

ولاختبار صحة هذا الفرض تم حساب (test المتوسطين مرتبطين للمقارنة بين متوسطي

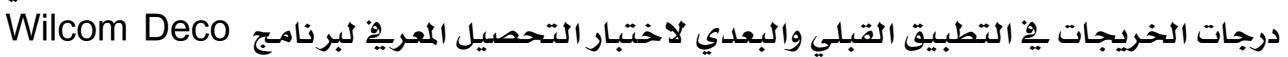

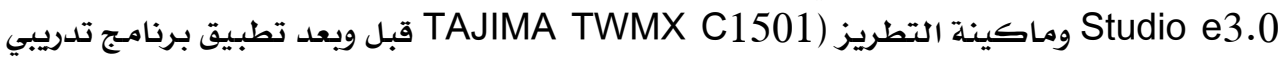

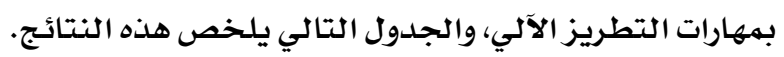
جدول (r) يوضح نتائج اختبار "ت" للمقارنة بين المتوسطين القبلي والبعدي لدرجات الخريجات يـ التطبيق القبلي والبعدي لاختبار التحصيل المعريف لبرنامج (TAJIMA TWMX C1501)

\begin{tabular}{|c|c|c|c|c|c|c|c|}
\hline درجة القبول & معدل الكسب & مستوي & قيمة "ت" & الدرية & الانحراف & المتوسط & التطبيق \\
\hline \multirow{2}{*}{ مقبولة لأنها تزيلد عن } & \multirow{2}{*}{1.80} & \multirow{2}{*}{ دالةج } & \multirow{2}{*}{133.671} & \multirow{2}{*}{24} & 1.42 & 6.72 & القبلي \\
\hline & & & & & 1.19 & 48.48 & البعدي \\
\hline
\end{tabular}

*تقاس الدلالة عند مستوي (ه.,.)

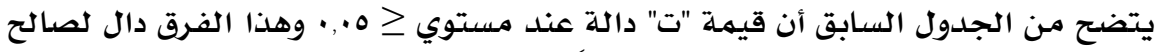

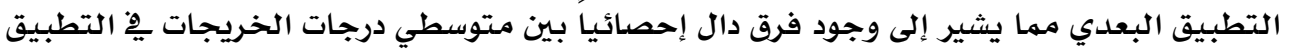

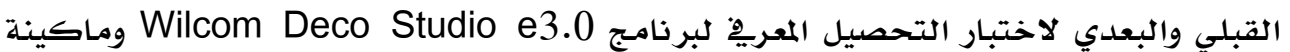

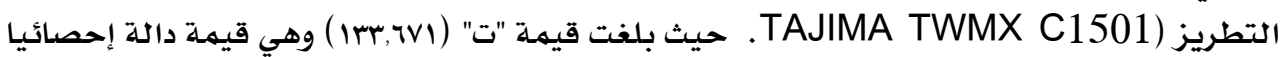

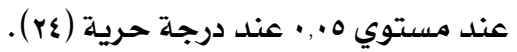

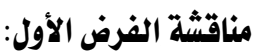

تم قبول الفرض الأول من فروض البحث والذي ينص علي: يوجد فرق دال إحصائياً عند

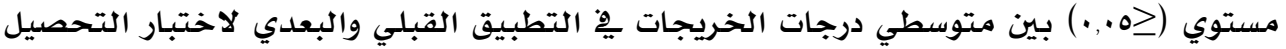

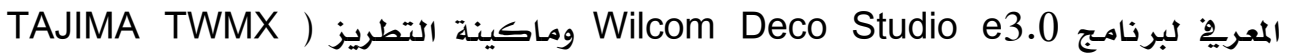
C1501 لصالح التطبيق البعدي.

ويرجع ذلك إلى تأثير البرنامج التدريبي بههارات التطريز الآلي بكل ما تضمنه من معارف

خاصة ببرنامج Wilcom Deco Studio e3.0 وماكينة التطريز ( TAJIMA TWMX .C1501

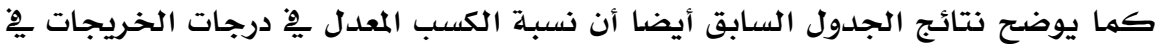

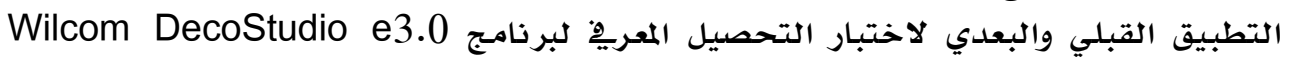

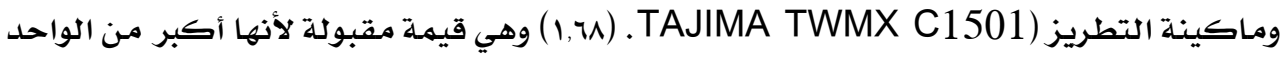
الصحيح، وبالتالي يمكن القول إن تطبيق برنامج تدريبي بههارات التطريز الآلي يتصف بلدرجة 
مقبولة من الفاعلية فيما يختص بتنمية التحصيل المعريِ فهو يحقق نسبة كسب معدل (ثابت

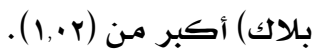

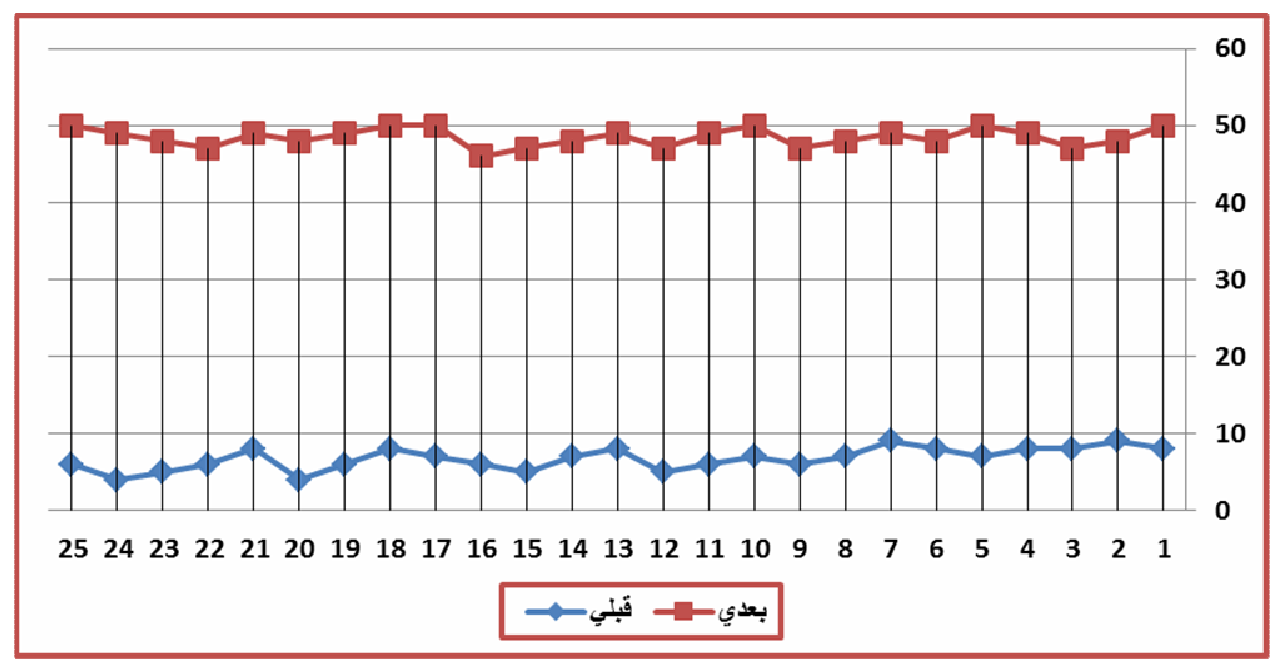

$$
\text { شكل (1) درجات الخريجات ِِّ التطبيق القبلي والبعدي لاختبار التحصيل المعريٌ }
$$

الفرض الثاني

للتحقق من صحة الفرض الثاني من فروض البحث والذي ينص علي: " يوجد فرق دال

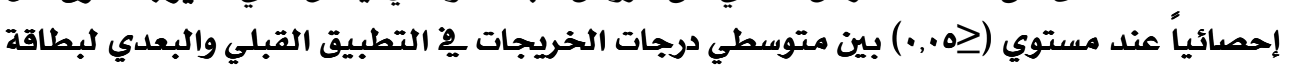

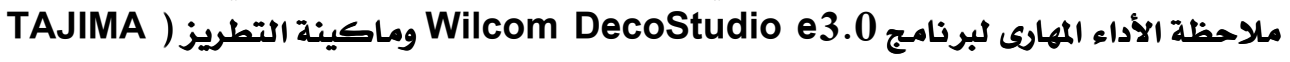

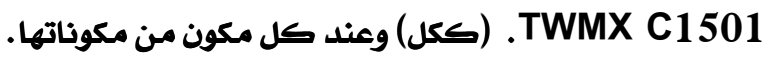
ولاختبار صحة هذا الفرض تم حساب (t-test لمتوسطين مـرتبطين) للمقارنة بين

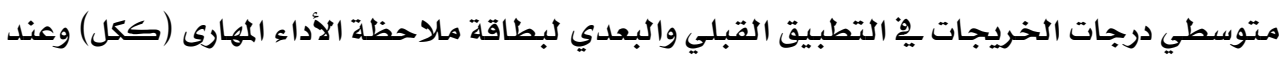

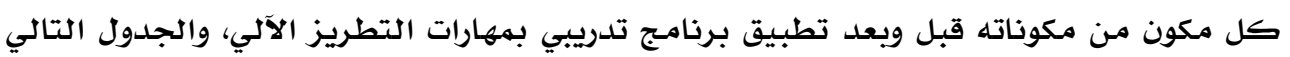
يلخص هذه النتائج. 


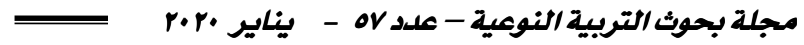

جدول (r) يوضح نتائج اختبار "ت" للمقارنة بين المتوسطين القبلي والبعدي لدرجات الخريجات يُ التطبيق وإيق

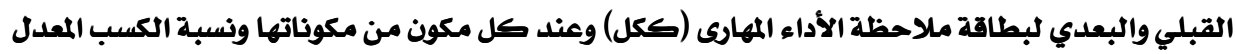

لبلانك

\begin{tabular}{|c|c|c|c|c|c|c|c|c|}
\hline درجة القبول & 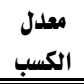 & مستوي & قيمة "ت" & درجة الحرية & الانحراف & التموسط & التطبيق & 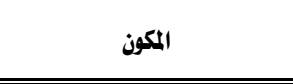 \\
\hline \multirow{2}{*}{ مقبولة لأنها تزيلد عن } & 1.51 & \multirow{2}{*}{ دالة* } & \multirow{2}{*}{17.097} & \multirow{2}{*}{25} & 0.46 & 16.28 & القبلي & \multirow{2}{*}{ قتح البرنامج ورسم الأجزاء } \\
\hline & 0 & & & & 8.34 & 45.12 & البعدي & \\
\hline \multirow{2}{*}{ مقبولة لأنها تزيلد عن } & 1.65 & \multirow{2}{*}{ | دالة* } & \multirow{2}{*}{316.564} & \multirow{2}{*}{25} & 0.54 & 30.28 & القبلي & \multirow{2}{*}{ لكتابة باللفة الإنجليزية والعربية } \\
\hline & 1 & & & & 0.87 & 89.56 & البعدي & \\
\hline \multirow{2}{*}{ مقبولة لأنها تزيد عن الصحيح } & 1.65 & \multirow{2}{*}{ | دالة* } & \multirow{2}{*}{367.915} & \multirow{2}{*}{25} & 0.37 & 17.16 & القبلي & \multirow{2}{*}{ المرسيرمة ومعاينة وحفظ التشريم وتعديل الأجزاء } \\
\hline & 8 & & & & 0.33 & 50.88 & البعدي & \\
\hline \multirow{2}{*}{ مقبولة لأنها تزيد عن الصحيح } & 1.65 & \multirow{2}{*}{ دالة* } & \multirow{2}{*}{329.670} & \multirow{2}{*}{25} & 0.74 & 29.28 & القبلي & \multirow{2}{*}{ أيقونات شريط الأدوات } \\
\hline & 7 & & & & 0.60 & 86.76 & البعدي البعي & \\
\hline \multirow{2}{*}{ مقبولة لأنها تزيلد عن } & 1.66 & \multirow{2}{*}{ 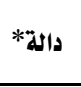 } & \multirow{2}{*}{511.943} & \multirow{2}{*}{25} & 0.33 & 21.12 & القبلي & \multirow{2}{*}{ تجهيز وتشفيل ماكينة التطريز } \\
\hline & 2 & & & & 0.28 & 62.92 & البعدي & \\
\hline مقبولة لأنها تزيلد عن & 1.63 & \multirow{2}{*}{ 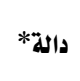 } & \multirow{2}{*}{134.047} & \multirow{2}{*}{25} & 1.01 & 114.12 & القبلي - القيل & \multirow{2}{*}{ بطاقة الملاحظة (ككل) } \\
\hline الواحلد الصحيح & 6 & & & & 8.30 & 335.24 & البعدي & \\
\hline
\end{tabular}

$$
\text { •. ثقاس الدلالة عند مستوي (0...) }
$$

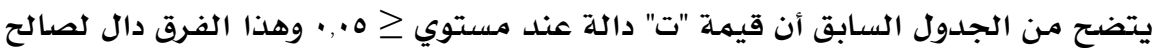

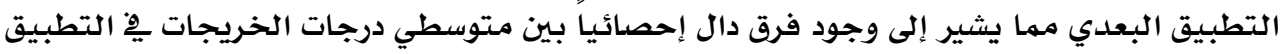

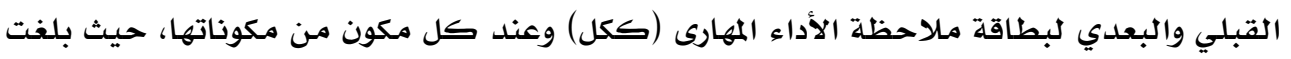

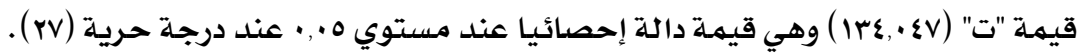

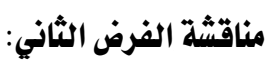

تم قبول الفرض الثاني من فروض البحث والذي ينص علي: يوجد فرق دال إحصائياً عند

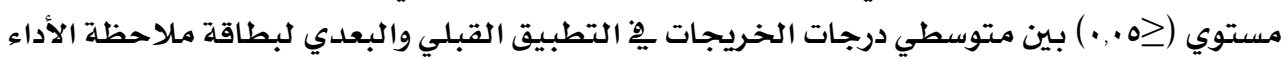
المهارى (ككل) وعند كل مكون من مكوناتها - لصالح التطبيق البعدي.

ويرجـ ذلك إلى تأثير برنامج تدريبي بمهارات التطريز الآلي بكل ما تضمنه من مهارات

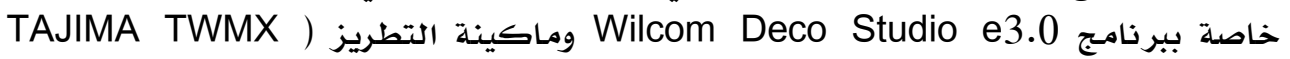
.C1501

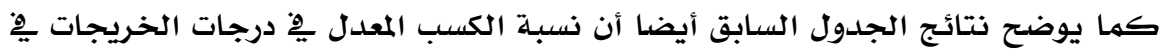

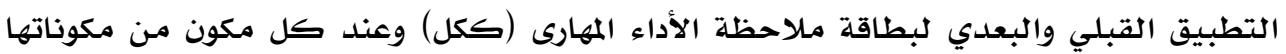

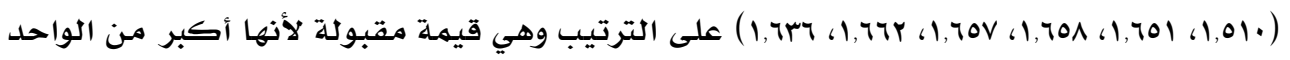

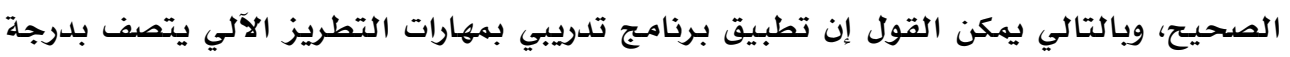


مقبولة من الفاعلية فيما يختص بتنمية الأداء المهارى فهو يحقق نسبة كسب معدل (ثابت بلاك)

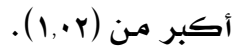

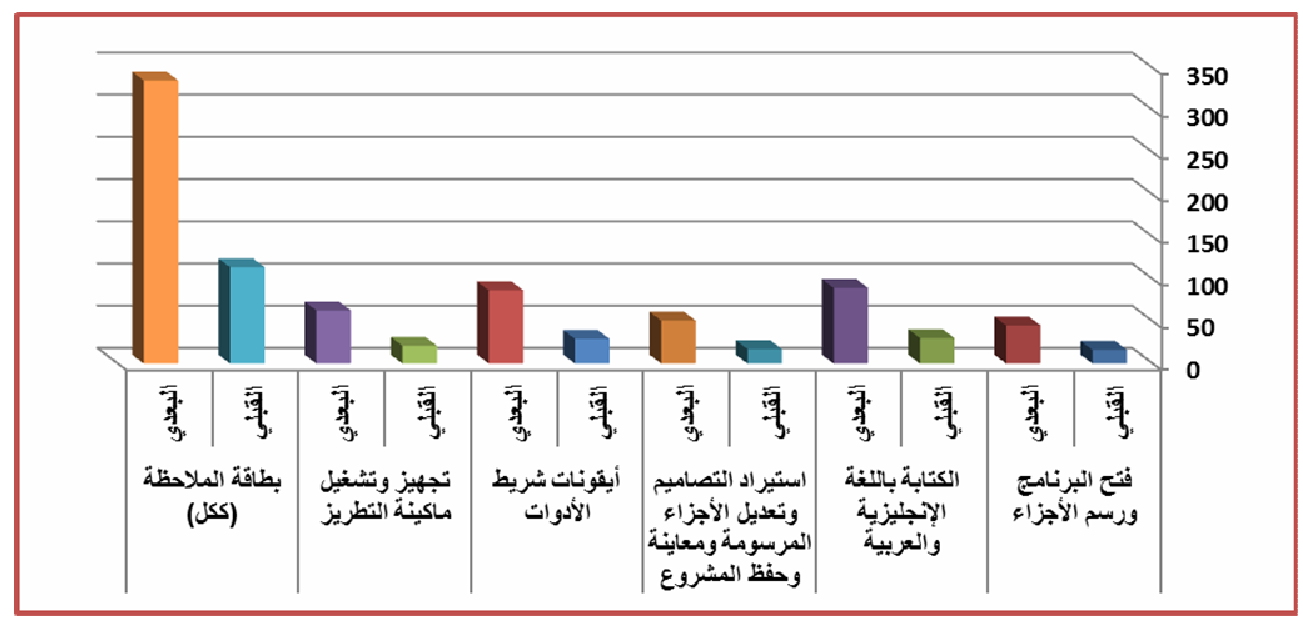

شكل (Y) متوسط درجات الخريجات مِ التطبيق القبلي والبعدي الأداء المهارى (ككل) وعند كل مكون من مكن مكوناتها

\section{الفرض الثالث}

للتحقق من صحة الفرض الثالث من فروض البحث والذي ينص علي: "توجد علاقة

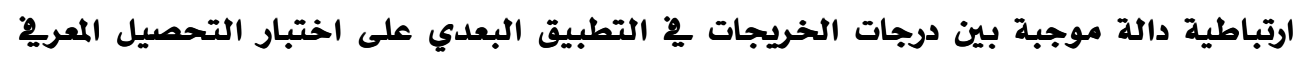

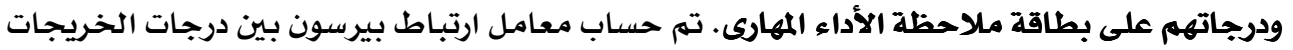

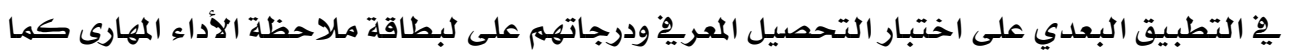
هو موضح بالجدول التالي: جدول (ع) يوضح قيمة "ر" ودلالتها الاحصائية للعلاقة الارتباطية بين متغيرات البحث

\begin{tabular}{|c|c|c|}
\hline بطاقة ملاحظة الأداء المهارى & اختبار التحصيل المعرفي & المتفيرات \\
\hline $0.756^{*}$ & & اختبار التحصيل المعرفي \\
\hline & & بطاقة ملاحظة الأداء المهارى \\
\hline
\end{tabular}

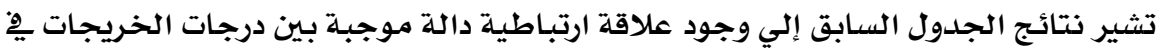

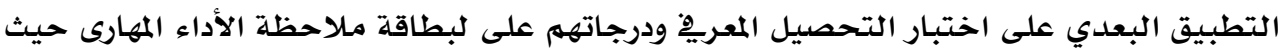

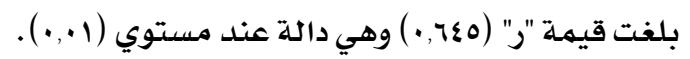
ويمكن للباحثة قبول الفرض الثالث من فروض البحث والذي ينص على " توجد علاقة

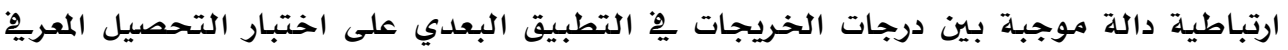




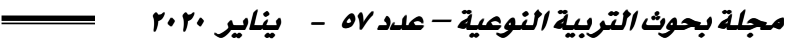

ودرجاتهم على لبطاقة ملاحظة الأداء المهارى، وبالتالي يهكن القول إن تطبيق برنامـج تدريبي بهـهارات

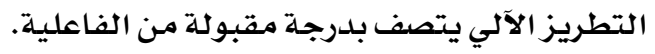

التتوصيات:

- - ضرورة تنظيم وتخطيط برامج تدريبية مستمرة لشباب الخريجين لتنمية مهارتهم المهنية. - مسايرة الاتجاهات الحديثة لتقنيات التطريز الالي يْ عمليات التدريب. - الاهتمام بتحديث المعارف والمهارات التي تطلبها شباب الخريجين لملاءمـة سوق العمل.

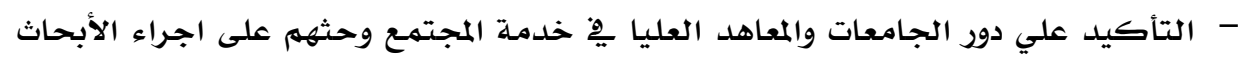
والدراسات الخاصة بالتطريز الآلي.

المراجـ

ا. أشرف محمد علوان: "تكنولوجيا الحشو ومدي تأثيرها علي جودة التصميم وإنتاج القميص الرجالي"،

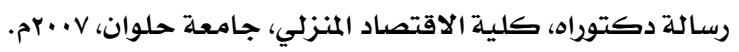

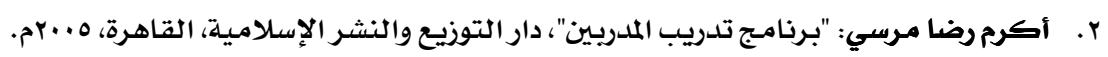

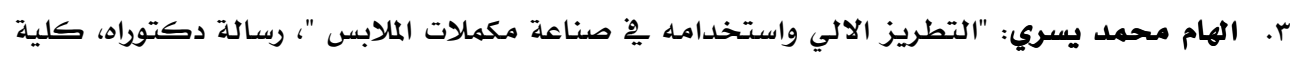

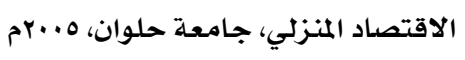

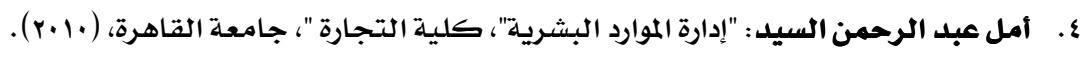

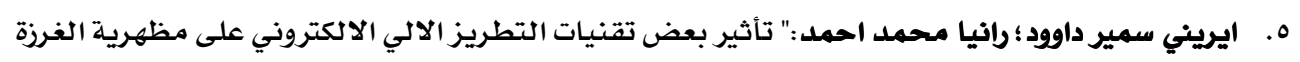

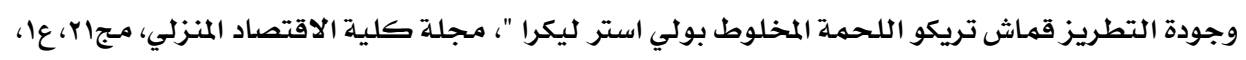

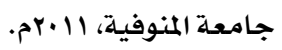
برنامجج الأمم المتحدة الائتماني: تقرير التنمية البشرية، بيروت، مركز دراسات .7

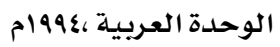
V. جيهان فهمي يوسف: "فاعلية برنامج تقنية الخياطة يِّ صناعة الملابس الجاهزة "، مجلة البحوث النوعية،

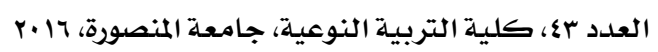

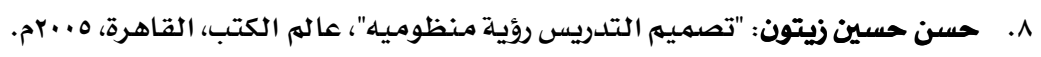

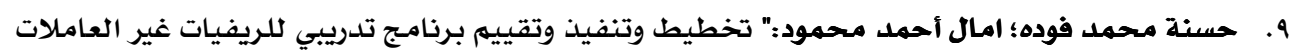

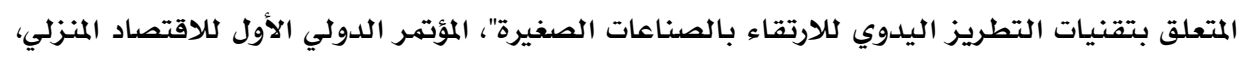

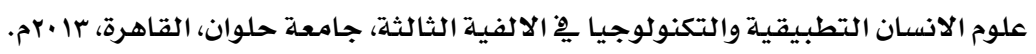

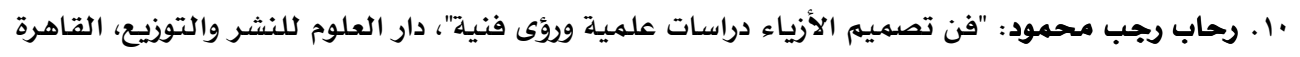
مr.lع، 11. سوسن عبد اللطيف رزق؛ وأمل محمد أبو زيد: "برنامج تدريبي مقترح لتنمية مهارات تصميم وإنتاج

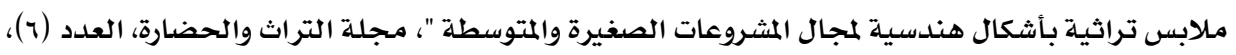

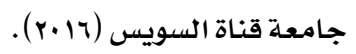


rا ـ شادية صلاح متولي؛ كريمة محمد حبيب الله:" برنامجج تدريبي لتنمية مهارات متدربات الوحدة الإنتاجية

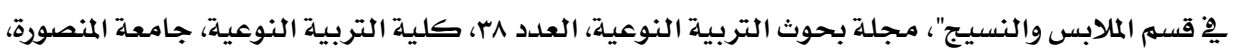
م. 10

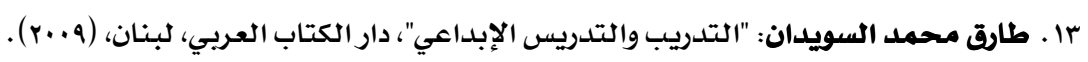

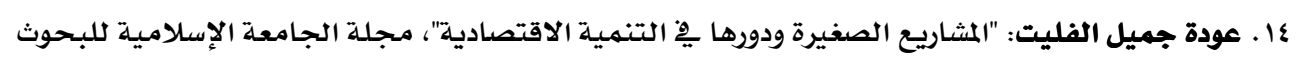

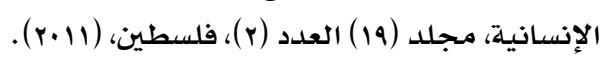

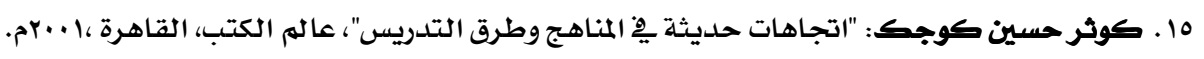

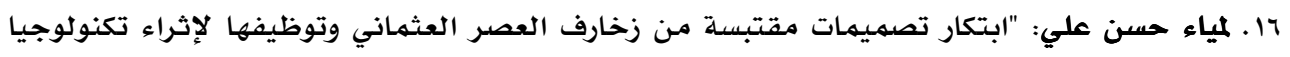

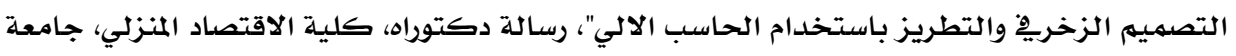

$$
\text { حلوان، 9... }
$$

: تأثير تقنيات التطريز الالي على مظهرية أقمشة الساتان، مجلة بحوث التربية النوعية، $.1 \mathrm{~V}$

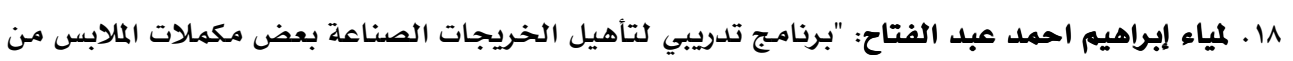

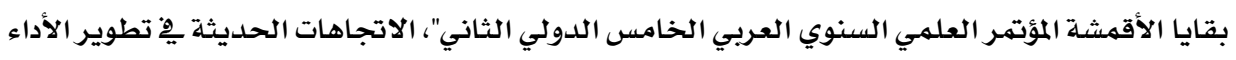

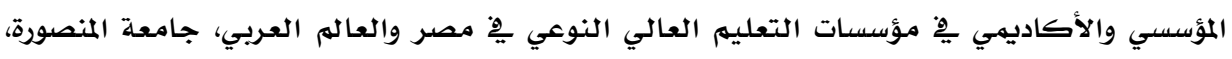

$$
\text { . }
$$

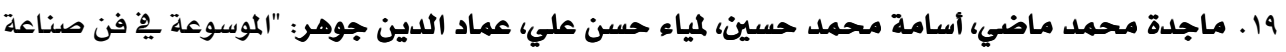

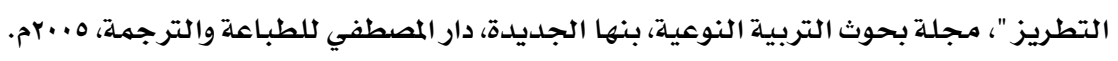

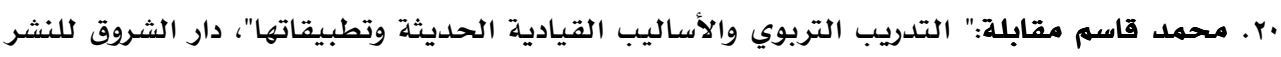

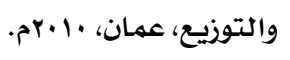

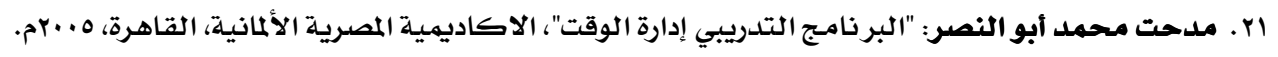

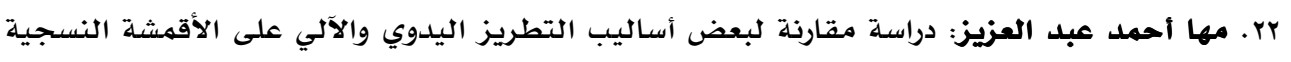

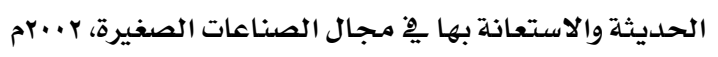

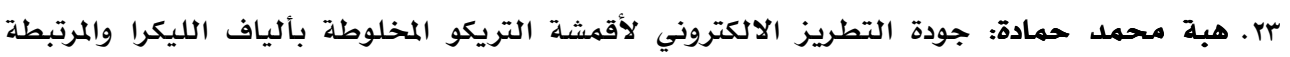

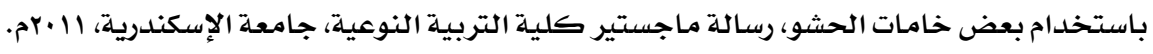

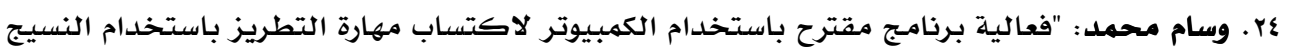

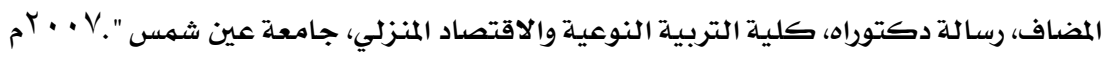
هr. يحيي على الدين حماد، ياسر فكري كشك: "تكنولوجيا التصنيع الغذائي والمشروعات الصغيرة، دار

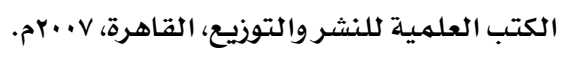

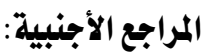

26. Anonymous: "The Effect of Program Organize for Sales Managers Training on Sale Value in Levi Strauss Company" UK, 2006. 


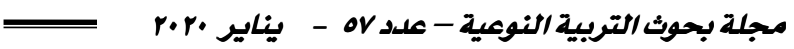

27. Chen, L intangible Cultural Heritage" Traditional Yi Embroidery Handicraft at Zhizuo and lts Characteristics" International Journal of $\mathrm{H}$ humanities and Social Science, 8(5), 2000.

28. Ross Lawrence Peckford: "Leadership Training in Human Resources Development" Canada, 2000.

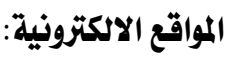

29. https://www.almaany.com

30. https://www.wilcom.com 


\section{Effectiveness of A training program For Developing Automated Embroidery Skills to Qualify Female Graduates to Establish Small and Medium Enterprises Abstract}

The research aims to prepare a training program For Developing Automated Embroidery Skills for female graduates to qualify them to set up small-medium sized projects, measure the effectiveness of the training program in developing cognitive aspects in the automatic embroidery of graduates to qualify them to establish small-medium projects, and measure the effectiveness of the training program in developing the performance aspects of the automatic embroidery skills of female graduates to qualify them to set up small projects Medium by providing them with the skills needed for the Wilcom DecoStudio e3.0 program and operating the TAJIMA (TWMX C1501) embroidery machine.

The research followed the applied approach, and the sample was a sample intentional number (25) from the graduates of colleges of home economics specializing in clothes and fabric and to have the desire to cooperate with the researcher, and she has low grades on the scale of the skill of automatic embroidery, and the age of the trainee is not less than 22 years.

The research found that the ratio of adjusted gain in the grades of graduates in the pre and post-application of the cognitive achievement test of the Wilcom DecoStudio e3.0 program and the embroidery machine (TAJIMA TWMX C1501. (1.68) is an acceptable value because it is greater than the correct one, and therefore it can be said that the application of a training program with skills Automated embroidery is characterized by an acceptable degree of effectiveness in terms of developing cognitive achievement, as it achieves a ratio of the rate of gain (black constant) greater than (1.02), and also the rate of modified gain in grades of graduates in the pre and post application of the skill performance observation card (as a whole) and when each of its components (1.510, 1.651, 1.658, 1.657, $1.662,1.636$ ) respectively $\mathrm{J}$ is an acceptable value because it is greater than the correct one, and therefore it can be said that the application of a training program with automated embroidery skills is characterized by an acceptable 
degree of effectiveness in terms of developing skill performance as it achieves a rate of gain (Black's constant) greater than (1.02), and the presence of a positive correlation between The degrees of graduates in post-application on the cognitive achievement test and their scores on the skill performance notecard, where the value of "t" (0.645) is a function at the level of (0.01), which confirms the existence of a positive correlation between the degrees of graduates in post-application on the cognitive achievement test and their degrees Ali card note performance I see, therefore, it can be said that the application of a training program with automated embroidery skills is characterized by an acceptable degree of effectiveness. 